\title{
Downscaling Landsat-8 land surface temperature maps in diverse urban landscapes using multivariate adaptive regression splines and very high resolution auxiliary data.
}

\author{
Joanna Zawadzka $^{\mathrm{a} *}$, Ron Corstanje ${ }^{\mathrm{a}}$, Jim Harris ${ }^{\mathrm{a}}$, Ian Truckell ${ }^{\mathrm{a}}$ \\ ${ }^{a}$ Centre for Environmental and Agricultural Informatics, School of Water, Energy and \\ Environment, Cranfield University, Bedfordshire, UK
}

\author{
*joanna.zawadzka@ @ranfield.ac.uk, Centre for Environmental and Agricultural \\ Informatics, School of Water, Energy and Environment, Cranfield University, \\ Cranfield, Bedfordshire, MK43 0AL, UK
}

We propose a method for spatial downscaling of Landsat-8 derived LST maps from $100(30 \mathrm{~m})$ resolution down to $2-4 \mathrm{~m}$ with the use of the Multiple Adaptive Regression Splines (MARS) models coupled with very high resolution auxiliary data derived from hyperspectral aerial imagery and large-scale topographic maps. We applied the method to four Landsat 8 scenes, two collected in summer and two in winter, for three British towns collectively representing a variety of urban form. We used several spectral indices as well as fractional coverage of water and paved surfaces as LST predictors, and applied a novel method for the correction of temporal mismatch between spectral indices derived from aerial and satellite imagery captured at different dates, allowing for the application of the downscaling method for multiple dates without the need for repeating the aerial survey. Our results suggest that the method performed well for the summer dates, achieving RMSE of $1.40-1.83 \mathrm{~K}$ prior to and $0.76-1.21 \mathrm{~K}$ after correction for residuals. We conclude that the MARS models, by addressing the non-linear relationship of LST at coarse and fine spatial resolutions, can be successfully applied to produce high resolution LST maps suitable for studies of urban thermal environment at local scales.

Keywords: land surface temperature, downscaling, urban, multivariate adaptive regression splines, remote sensing 


\section{Introduction}

Urban environments are becoming an increasingly important habitat for humans, with over $68 \%$ of global population being forecast to inhabit cities by year 2050 (UN, 2018). Urbanisation and associated changes to land cover and urban structure has been linked to significant thermal changes to the environment, termed the urban heat island effect, where the air and surface temperatures of cities are typically much higher than surrounding landscapes (Bornstein, 1968; Pitman et al., 2015), with implications to both ecological status of populations (Shochat et al., 2006) as well as human health and wellbeing (Kalkstein and Smoyer, 1993; Lee et al., 2003). There is therefore a need for regulation of air temperatures in the cities, and this role can be fulfilled by urban greenspaces, which have been shown to reduce the intensity of urban heat islands subject to appropriate size and configuration in studies relying on coarser-resolution satellite-derived land surface temperature (LST) observations (Asgarian et al., 2015; Kong et al., 2014; Zhou et al., 2017) and studies utilising on-the-ground-measurements of air temperature associated with paved-vegetated area gradient (Takebayashi and Hideki, 2017; Yu and Hien, 2006).

Although the air-temperature studies provide an accurate picture of thermal gradients over the boundary between contrasting urban land covers, these are often limited to a relatively small study area for which air temperatures can be measured simultaneously across its full extent. Remotely sensed LST data offer an alternative to capture data for relatively large areas, however, the spatial resolution of such datasets, typically ranging from $60 \mathrm{~m}$ to $1 \mathrm{~km}$, is insufficient to capture local interactions of LST in relation to the heterogeneous character of land cover in the cities (Lo, Quattrochi, and Luvall 1997). Very high spatial resolution thermal imagery (5-10m or higher) can be 
acquired from aerial or UAV surveys, however, these are typically costly, especially for large areas or monitoring purposes, requiring repeated data acquisition.

We propose that the study of interactions between LST and urban form could be enhanced by the implementation of very high spatial resolution LST maps obtained in the process of LST downscaling whereby high resolution LST maps are derived from lower resolution thermal data based on the existing statistical relationship between LST and spectral indices or land cover information (Zhan et al. 2013). As so far, LST downscaling studies carried out for urban areas have targeted relatively coarse spatial resolutions, with final downscaled spatial resolutions comprising $1 \mathrm{~km}$ (Weng and $\mathrm{Fu}$ 2014), 480-120m (Bonafoni 2016), 90m (Yang et al., 2010; Zhan et al., 2012; Yang et al., 2017), 60m (Zhan et al. 2012), 50m (Feng et al. 2015), and 30m (Bonafoni et al. 2016), with downscaling factors, defined as the ratio between the observed and downscaled spatial resolution (Zhou et al., 2016; Bonafoni and Tosi, 2017), rarely exceeding 10. Only one recent study, Bonafoni and Tosi (2017), attempted the downscaling process to $2 \mathrm{~m}$ spatial resolution.

In this work, we set out to generate very high resolution LST images ( 2 to $4 \mathrm{~m}$ ) for urban areas based on the relationship between Landsat 8 coarse resolution LST data and auxiliary data comprising very high resolution spectral indices derived from an aerial survey at 2 and $4 \mathrm{~m}$ spatial resolution as well as $2 \mathrm{~m}$ resolution fractional cover of paved and water-covered areas derived from topographic maps, for both summer and winter conditions. Given the complex relationship between LSTs and the auxiliary datasets, and the possibility that simple regression models (e.g. ordinary least squares linear regression) may not be able to reveal the causes of the spatial variation in LST (Weng and $\mathrm{Fu} 2014$ ), we decided to test our methodology with the use of the Multiple Adaptive Regression Splines (MARS) capable of fitting different regression functions into 
different regions of n-dimensional data (Friedman, 1991). As so far, very few environmental studies have used the MARS method to predict spatial distribution of environmental phenomena, limited mostly to the fields of digital soil mapping ( Piikki et al. 2015; Piikki and Söderström 2017) and landslide detection (Wang et al. 2015), and this is the first study known to the authors that uses MARS in LST downscaling. Further novelty of our approach consists in adjustments of spectral indices derived from very high resolution aerial imagery for the values of equivalent spectral indices derived from coarser resolution satellite imagery acquired together with the thermal data - a method aiming at mitigation of the temporal mismatch between acquisition dates of aerial and satellite imagery. Such adjustments can potentially allow for multi-temporal assessments of LST at very high spatial resolution without the need of repeated acquisition of very high resolution multispectral data, limited only by the availability of cloud-free satellite data.

The specific objectives of this study are therefore to (1) present an LST downscaling method at rarely explored spatial resolutions for both summer and winter conditions, (2) suggest a method for enhancing the accuracy of the downscaled maps when there is a temporal mismatch between the acquisition dates of coarse resolution LST data and the fine resolution auxiliary imagery from which scaling factors are derived, facilitating multi-temporal downscaling of the LST maps without the need of re-occurring aerial surveys, and (3) evaluate the potential of Multivariate Adaptive Regression Splines method to accurately downscale LST in urban environments.

We envisage that the resulting very fine resolution LST images could provide much-needed evidence for the relationship between the structure of urban fabric and thermal environment at microscales (Jenerette et al. 2015; Norton et al. 2015; Sanusi et al. 2016), essential for an improved design of urban areas that is set to address 
challenges imposed by urban expansion, potentially exacerbated by the effects of climate change.

\section{Materials and methods}

\section{Study area}

The study area (Figure 1) comprises the extents of the hyperspectral aerial imagery available for three English towns: Milton Keynes (MK) $\left(52^{\circ} 0^{\prime} \mathrm{N}, 0^{\circ} 47^{\prime} \mathrm{W}\right.$, appr. $\left.122 \mathrm{~km}^{2}\right)$, Bedford (BD) $\left(52^{\circ} 8 \mathrm{~N}, 0^{\circ} 27^{\prime} \mathrm{W}\right.$, appr. $\left.60 \mathrm{~km}^{2}\right)$, and Luton/Dunstable (LT) $\left(51^{\circ} 52^{\prime} \mathrm{N}, 0^{\circ} 25^{\prime} \mathrm{W}\right.$, appr. $\left.86 \mathrm{~km}^{2}\right)$, characterised with contrasting histories that influenced collective diversity of urban form within the three towns, making them representative of small- to medium sized British towns' structure. Milton Keynes is a recently designed garden city abundant in parks and greenspaces, characterised by a grid of dual-carriageways dissecting the town into clearly defined neighbourhoods. Bedford is a medieval market town characterised with densely built-up city centre with several parks and residential areas located at the outskirts. Luton, on the other hand, is an industrial-era town characterised with a modern densely built-up city centre and residential areas composed of terraced housing. Further information on land cover in the three towns is available in Grafius et al. $(2017,2016)$. From climatic perspective, the three towns are located within temperate oceanic climate (Köppen-Geiger climate classification system) with the highest monthly average air temperatures of approximately $22{ }^{\circ} \mathrm{C}$ in July and lowest temperatures of approximately $1{ }^{\circ} \mathrm{C}$ observed in February, and the average annual precipitation of 597.6, 657.4, and $712.3 \mathrm{~mm}$ for BD, MK and LT respectively. 


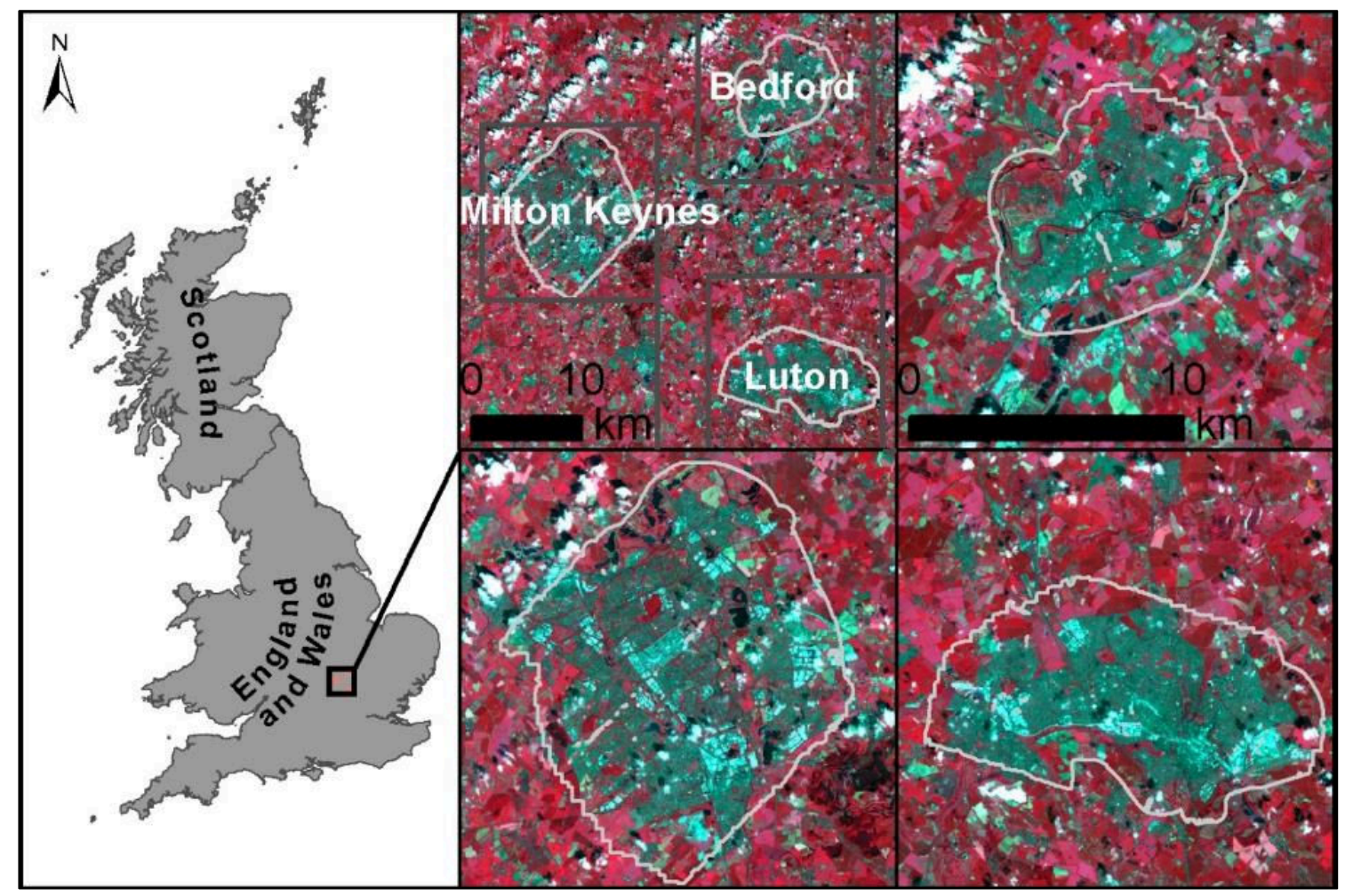

Figure 1 Location of the study area displayed over a backdrop of the NIR-Red-Green band composite image of the Landsat 8 dataset acquired on 8 Jul 2013. The outlines shown correspond to the extent of the high-resolution hyperspectral aerial imagery available for the three towns limiting the area to which the downscaling procedure could be applied.

\section{Data used in LST mapping and downscaling}

LST maps at medium spatial resolution were derived from TIR bands of Landsat 8 scenes (WRS path 202 row 24) comprising Milton Keynes, Bedford and Luton, acquired from USGS Earth Explorer for two winter and two summer dates (Table 1), which allowed for testing of the downscaling methodology under various thermal and phenological conditions. Selection of the dates was restricted by the availability of cloudless images for all three towns captured in a single scene. Total atmospheric water content required for the conversion of the thermal bands of satellite imagery to land surface temperature was estimated from the Near Infrared Total Precipitable Water Vapour Test Result (MOD05_L2) dataset derived from Terra MODIS satellite at $1 \mathrm{~km}$ 
spatial resolution (Supplementary Materials Section 1 Table 1). Emissivity values required for the conversion of thermal radiances to land surface temperature were estimated from the MODIS UCSB Emissivity Library that stores emissivity values of common land cover materials for a high range of spectral bands. LST downscaling was carried out based on high resolution auxiliary datasets, referred here to as LST predictors, acquired from two different sources. Firstly, hyperspectral aerial imagery covering the visible (VIS), near infrared (NIR) and short wave (SWIR) infrared spectra was acquired in June, July and September 2012 with the Eagle (253 bands in the range of $0.4-1 \mu \mathrm{m})$ and Hawk (233 bands in the range of $1-2.5 \mu \mathrm{m})$ sensors mounted on the NERC Airborne Research and Survey Facility (ARSF) Data Analysis Node airplane. Spatial resolutions of the data ranged from $2 \mathrm{~m}$ for the Eagle ( $4 \mathrm{~m}$ in Luton) and $4 \mathrm{~m}$ for the Hawk sensors. Secondly, the Ordnance Survey MasterMap topographic map was used to map the locations of paved urban surfaces and buildings as well as surface water within the three towns at $2 \mathrm{~m}$ spatial resolution.

Table 1 Spatial datasets used in land surface temperature mapping and downscaling for Milton Keynes, Bedford and Luton.

\begin{tabular}{|c|c|c|c|c|}
\hline Dataset & $\begin{array}{l}\text { Spatial } \\
\text { coverage }\end{array}$ & $\begin{array}{l}\text { Date of } \\
\text { acquisition }\end{array}$ & $\begin{array}{l}\text { Time of } \\
\text { acquisition }\end{array}$ & $\begin{array}{l}\text { Spatial } \\
\text { resolution }\end{array}$ \\
\hline $\begin{array}{l}\text { Hyperspectral } \\
\text { aerial imagery }\end{array}$ & $\begin{array}{l}\text { Milton Keynes } \\
\text { Luton } \\
\text { Bedford }\end{array}$ & $\begin{array}{l}\text { 24 Jul } 2012 \\
\text { 26 Jul } 2012 \\
\text { 05 Sep } 2012 \\
\text { 06 Sep } 2012\end{array}$ & $\begin{array}{l}14: 00-16: 03 \\
09: 39-11: 52 \\
10: 47-12: 19 \\
13: 18-15: 43\end{array}$ & $\begin{array}{l}2 \mathrm{~m} \text { VIS and } \\
\text { NIR (BD and } \\
\text { MK) } \\
4 \mathrm{~m} \text { VIS and NIR } \\
(\mathrm{LT}) \\
4 \mathrm{~m} \text { SWIR }\end{array}$ \\
\hline Landsat 8 & $\begin{array}{l}\text { Milton Keynes, } \\
\text { Bedford and } \\
\text { Luton }\end{array}$ & $\begin{array}{l}\text { 06 Jun } 2013 \\
\text { 08 Jul } 2013 \\
\text { 02 Feb } 2014 \\
\text { 19 Jan } 2015\end{array}$ & $\begin{array}{l}11: 00 \\
11: 00 \\
10: 59 \\
10: 58\end{array}$ & $\begin{array}{l}\text { 30m VIS-NIR- } \\
\text { SWIR } \\
30(100) \mathrm{m} \text { TIR }\end{array}$ \\
\hline $\begin{array}{l}\text { MODIS NIR } \\
\text { water vapour } \\
\text { (MOD05_L2) }\end{array}$ & $\begin{array}{l}\text { Milton Keynes, } \\
\text { Bedford, Luton }\end{array}$ & $\begin{array}{l}\text { 06 Jun } 2013 \\
\text { 08 Jul } 2013 \\
\text { 02 Feb } 2014 \\
\text { 19 Jan } 2015 \\
\end{array}$ & $\begin{array}{l}12: 00 \\
12: 00 \\
12: 00 \\
12: 05 \\
\end{array}$ & $1 \mathrm{~km}$ \\
\hline OS MasterMap & $\begin{array}{l}\text { Milton Keynes, } \\
\text { Bedford, Luton }\end{array}$ & 2006 & Not applicable & $\begin{array}{l}1: 1,250- \\
1: 10,000 \text { scale }\end{array}$ \\
\hline
\end{tabular}




\section{Methodology for land surface temperature mapping at medium spatial}

resolution

Availability of two TIR bands in Landsat-8 imagery allowed for the implementation of the split window algorithm as described in Jimenez-Munoz et al. (2014) to this case study (Figure 2). Emissivity for bands 10 and 11 of Landsat 8 sensor was estimated with the simplified NDVI thresholds method, as presented in Sobrino et al. (2008), with a modification to allow for the assignment of emissivity values for pixels occupied by water as well as built-up areas rather than soil (refer to Section 1 in Supplementary Materials for the detailed description of the undertaken approach).

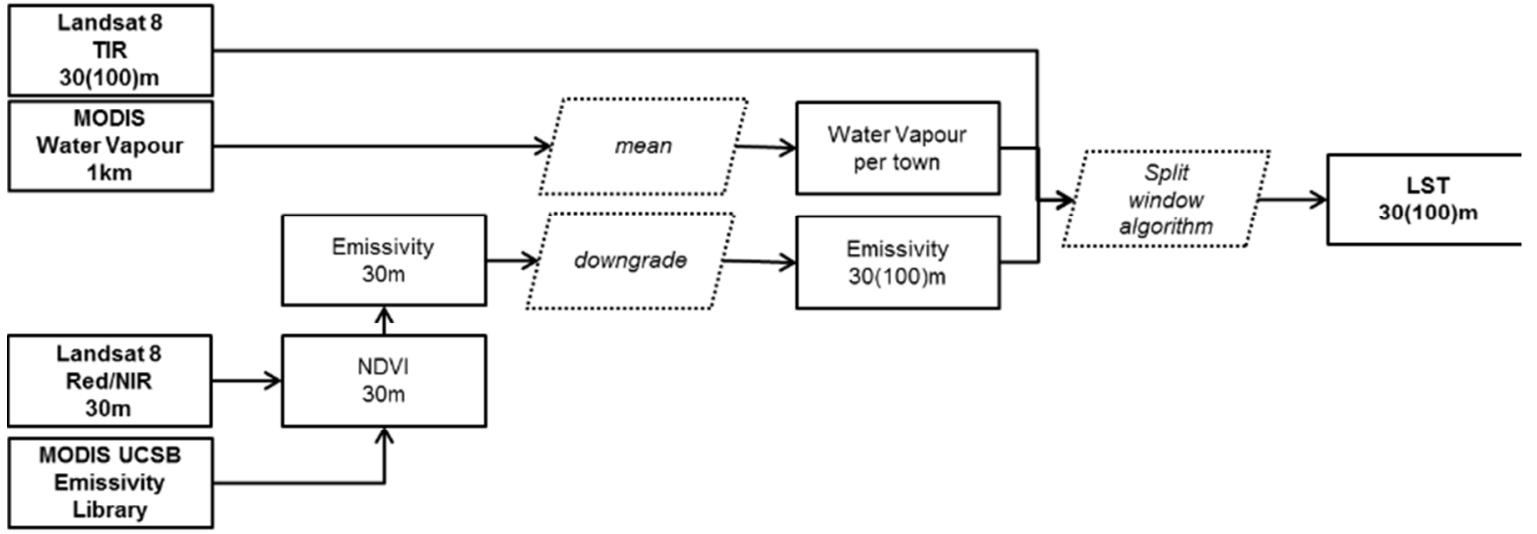

Figure 2 Schematic of LST mapping from satellite imagery implemented in this study for each town and date of Landsat 8 images.

Methodology for land surface temperature downscaling

Preparation of LST predictors

Spectral indices. We selected several spectral indices describing the distribution of paved vs vegetated areas (NDVI, NDBI, BUAEI) as well as type of surface materials (CMR, FMR, IOR) potentially distinguishing between built-up areas and bare soil (Supplementary Materials Section 2 Table 1) as proxies for the distribution of LST values across our three towns, and derived them both from satellite and the 
hyperspectral aerial imagery available for the three towns. For consistency with the satellite data, pixel values of the multiple hyperspectral bands of the aerial imagery equivalent to the spectral ranges of individual bands in the Landsat 8 data were summed prior to the calculations of spectral indices.

As a result of different acquisition dates, there was a temporal mismatch, both in terms of months and years, between the Landsat 8-derived LST maps and spectral indices derived from the very high resolution aerial imagery, which we considered as a potential limiting factor for the accuracy of our downscaled maps, especially important for the winter scenes, due to different ground conditions in terms of vegetation development stages and paved area extent. We therefore devised a procedure whereby the spectral indices derived from aerial imagery were adjusted to the values of equivalent Landsat-8 indices for each date and town, addressing the differences in spectral indices due to different phenological stages of vegetation in different seasons of the year represented by the satellite imagery.

The adjusting procedure for the very high resolution spectral indices was similar to the regression kriging method (model B in Odeh et al., (1995)) whereby (1) the aerialbased spectral indices were aggregated to the spatial resolution of corresponding Landsat 8-based indices (30m) with the use of a mean function within corresponding 30x30m blocks of pixels, (2) differences, i.e. residuals, between the Landsat 8-based indices and aggregated aerial-based indices were calculated, (3) the residuals were kriged with the ordinary kriging method (Cressie 1988) and saved as raster layers at a spatial resolution of the aerial imagery-based indices (2m), and (4) the kriged residuals were added to the aerial imagery-based indices at their native very high resolution. Kriging of the residuals ensured the distribution of the differences in spectral indices values was based on their spatial dependency, avoiding the introduction of box-shaped 
artefacts sourced from the Landsat 8-derived spectral indices (Mukherjee, Joshi, and Garg 2015), whilst retaining the expected "crisp" character of the indices at the higher resolution, provided that the variogram parameters (nugget, sill and range) were set to minimise the error of the fitted model. The adjusting procedure was applied individually for each index, town and date, yielding 24 (6 indices $\mathrm{x} 4$ dates) raster maps for each town. Since the kriged residual layer was saved at $2 \mathrm{~m}$ resolution, any indices that included SWIR wavebands captured at $4 \mathrm{~m}$ resolution by the Hawk sensor, acquired an intermediary resolution of 2 to $4 \mathrm{~m}$. The performance of the adjusting procedure was evaluated based on the comparison of correlation coefficients derived between pairs of Landsat 8-derived spectral indices and the upscaled to $30 \mathrm{~m}$ resolution (mean of very high resolution pixels within corresponding $30 \mathrm{~m}$ pixels) adjusted or original (unadjusted) spectral indices sourced from the aerial imagery.

Maps of water and manmade surfaces. Manmade and water percent cover raster maps at a $2 \mathrm{~m}$ spatial resolution were derived from the OS MasterMap topographic maps available in a vector format for the three towns. The generation of these maps involved a series of GIS operations whereby the percentage coverage of land cover classes generally perceived as impervious (buildings, roads, paths, railways and structures) or as water (inland water) were calculated within $2 \times 2 \mathrm{~m}$ polygons corresponding to pixel locations in the aerial hyperspectral imagery, and subsequently converted to raster maps representing the percentages at the scale of 0 to 1 . This method of map production, as opposed to a simpler method of vector to raster conversion, ensured accountability for mixed pixels as well as continuity of narrow linear features such as paths, narrow roads and streams. 
Land surface temperature downscaling using regression methods

In our downscaling methodology, we assessed the performance of multivariate regression adaptive splines (MARS), to produce LST maps at high spatial resolution (2/4m) from LST maps at medium $(30(100) \mathrm{m})$ spatial resolution. We refer to the medium resolution as $30(100) \mathrm{m}$ due to the fact that the Landsat 8 TIR bands used to map LST in this study are captured at 100m resolution and are subsequently resampled to $30 \mathrm{~m}$ by data supplier with the bilinear convolution method to match the resolution of the remaining spectral bands. The downscaling procedure comprised three stages: (1) model development (Figure 3), (2) model deployment and downscaled map generation, and (3) post-processing of the downscaled maps.

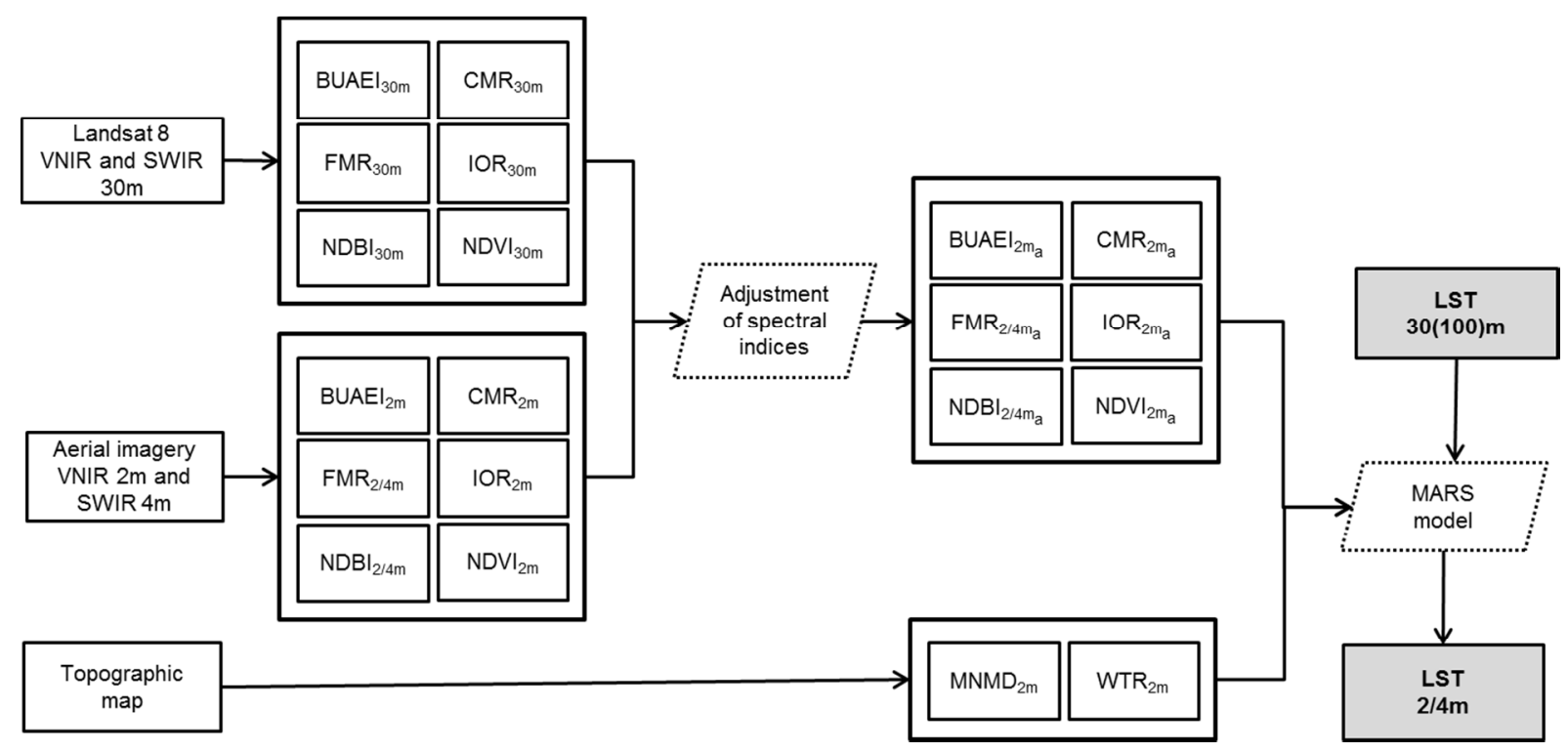

Figure 3 Schematic of the LST downscaling model.

In the first stage, model development, the relationship $f()_{\text {MARS }}$ between $\operatorname{LST}_{30(100) \mathrm{m}}$ and LST scaling factors were established MARS regression methods (Equation 1). Models for the two summer and two winter dates were implemented in the Statistica 64 software separately for each town. It has to be noted that we used all data pixels to develop the models, which increased the processing time to up to several days per town 
on a 64GB RAM 12 Core-processor PC. The processing time was increased due to the fact that very high resolution, rather than upscaled to the LST data resolution, ancillary datasets were used in model development, which constitutes a marked methodological difference to numerous published methods (Kustas et al. (2003); Agam et al. (2007); Mukherjee et al. (2014); Bonafoni et al. (2016)).

$L S T_{30(100) m}=$ $f_{M A R S}\left(B U A E I_{2 / 4 m_{a}}, C M R_{2 / 4 m_{a}}, F M R_{2 / 4 m_{a}}, I O R_{2 m_{a}}, M N M D_{2 m}, N D B I_{2 / 4 m_{a}}, N D V I_{2 m_{a}}, W T R_{2 m}\right)$ , where:

$\mathrm{LST}_{30(100) \mathrm{m}}$ - Landsat 8-derived land surface temperature at its native coarse spatial resolution,

$\mathrm{BUAEI}_{2 / 4 \mathrm{ma}}$ - built-up area extraction spectral index at 2/4m spatial resolution, $\mathrm{CMR}_{2 / 4 \mathrm{ma}}$ - clay minerals ratio spectral index at $2 / 4 \mathrm{~m}$ spatial resolution, $\mathrm{FMR}_{2 / 4 \mathrm{ma}}$ - ferrouse minerals spectral ratio index at $2 / 4 \mathrm{~m}$ spatial resolution, $\mathrm{IOR}_{2 / 4 \mathrm{ma}}$ - iron oxide ratio spectral index at $2 / 4 \mathrm{~m}$ spatial resolution, $\mathrm{MNMD}_{2 \mathrm{~m}}$ - percentage of impervious "manmade" surfaces within a $2 \mathrm{~m}$ resolution pixel,

$\mathrm{NDBI}_{2 / 4 \mathrm{ma}}$ - normalised difference built-up spectral index at $2 / 4 \mathrm{~m}$ spatial resolution, $\mathrm{NDVI}_{2 \mathrm{ma}}$ - normalised difference vegetation spectral index at $2 \mathrm{~m}$ spatial resolution, $\mathrm{WTR}_{2 \mathrm{~m}}$ - percentage of water within a $2 \mathrm{~m}$ resolution pixel.

All the above spectral indices at 2 or 2 to $4 \mathrm{~m}$ spatial resolution were extracted from hyperspectral aerial imagery and adjusted for on-the-ground conditions at dates of interest adding the kriged difference between these and equivalent Landsat8-derived indices. 
In the second stage, model deployment and map generation, the downscaled $\widehat{\mathrm{LST}}_{\mathrm{MARS} 2 / 4 \mathrm{ma}}$ values were predicted in Statistica Software using equations listed in Supplementary Materials Section 4 Tables 1-3and mapped as 2m resolution raster maps, using the 'raster' and 'sp' packages in R software.

In the post-processing stage, the core $\widehat{L S T}_{\mathrm{MARS} 2 / 4 m a}$ downscaled maps were adjusted for residuals $\Delta L S T_{30(100) m}$ calculated between the Landsat 8 derived maps $L S T_{30(100) m}$ and upscaled predicted maps $\widehat{L S T}_{30(100) m}$ to match the spatial resolution of the Landsat 8 - derived LST maps, to generate the ${\widehat{L S T^{\prime}}}_{\text {MARS2/4m map }}$ (Equations 2 and 3).

$$
\begin{aligned}
& \Delta \mathrm{LST}_{30(100) \mathrm{m}}=\mathrm{LST}_{30(100) \mathrm{m}}-\widehat{L S T}_{30(100) \mathrm{m}} \\
& \widehat{L S T}_{\text {MARS } 2 / 4 m}^{\prime}=\widehat{L S T_{\mathrm{MARS} 2 / 4 m}}+\Delta L S T_{30(100) m}
\end{aligned}
$$

The predicted $\widehat{L S T}_{\text {MARS2/4m }}$ maps were upscaled to $\widehat{L S T}_{30(100) m}$ by first resampling to $100 \mathrm{~m}$ spatial resolution at which the Landsat 8 TIR data are captured, and subsequently resampling to $30 \mathrm{~m}$ resolution to generate $\widehat{L S T}_{30(100) m}$ using the bilinear convolution method, consistent with the resampling method of the TIR bands carried out by the Landsat 8 data provider. These $\widehat{L S T}_{30(100) m}$ maps were then resampled to $2 \mathrm{~m}$ spatial resolution with the nearest neighbour method, which maintained the pixel values at 30m spatial resolution, to enable the calculation presented in Equation 3.

For method comparison purposes, we also developed MARS models using scaling factors at 30m spatial resolution, and multiple regression (MR) models developed with very high resolution scaling factors that were or were not adjusted for the temporal mismatch between acquisition dates of aerial and satellite imagery. 


\section{Verification of the results}

Due to unavailability of alternative land surface temperature datasets, other than the Landsat 8-derived LST maps, that could have been used to independently validate the downscaled LST maps, the performance of the MARS models was verified by the adjusted $\mathrm{R}$ squared metric returned at the stage of model development as well as the calculation of the root mean square error (RMSE) between the Landsat 8-derived and downscaled maps. RMSE was calculated in two modes. Firstly, RMSE $2 / 4 \mathrm{~m}$ was calculated from differences between the observed $L S T_{30(100) m}$, resampled to $2 \mathrm{~m}$ spatial resolution with the nearest neighbour method to enable the calculations presented in equations 4 and 5, and downscaled maps $\widehat{L S T}_{\mathrm{MARS} 2 / 4 m}$ (Equation 4).

$$
R M S E_{2 / 4 m}=\sqrt{\frac{1}{N} \sum_{i=1}^{N}\left(L S T_{30(100) m}-\widehat{L S T} T_{\mathrm{MARS} 2 / 4 m}\right)^{2}}
$$

Secondly, $R M S E_{2 / 4 m}^{\prime}$ was calculated as a comparison between the Landsat 8derived maps and downscaled and adjusted for residuals $\left(\Delta L S T_{30(100) m}\right)$ maps ${\widehat{L S T^{\prime}}}_{\text {MARS2/4m }}$ (Equation 5).

$$
R M S E_{2 / 4 m}^{\prime}=\sqrt{\frac{1}{N} \sum_{i=1}^{N}\left(L S T_{30(100) m}-{\widehat{L S T^{\prime}}}_{\text {MARS } 2 / 4 m}\right)^{2}}
$$

\section{Results and analysis}

\section{LST predictors}

Prior to inclusion in the LST downscaling models, spectral indices derived from hyperspectral imagery at 2 to $4 \mathrm{~m}$ spatial resolution were adjusted for the values of equivalent spectral indices derived from available satellite images to correct for temporal mismatch caused by different years and seasons of data acquisition. We analysed correlation coefficients calculated between pairs of the satellite-derived indices and the aggregated adjusted or original spectral indices derived from the very high 
resolution hyperspectral data to find that the adjusting procedure was highly successful achieving correlation coefficients as high as 0.80-0.99 for multiple spectral indices, especially in the summer (Supplementary Materials Section 3 Table 1), with some improvement observed in winter. Scatterplots constructed between pairs of equivalent Landsat 8 and aerial imagery-derived spectral indices, both before and after application of the adjustment procedure (Supplementary Materials Section 3 Figures 1-4), confirm that in many cases, and especially for the summer dates, the ranges of values of the latter set of indices were satisfactorily matched to the ranges of the satellite-derived indices, achieving a nearly one-to-one relationship in the case of IOR, FMR and NDBI, with NDVI achieving strong, albeit slightly weaker, agreement. The improved predictive power of the adjusted spectral indices was confirmed by adjusted $\mathrm{R}^{2}$ values obtained by multiple regression models constructed with both adjusted and non-adjusted spectral indices, which doubled from circa 0.35 to $0.6-0.8$ for summer conditions (Supplementary Materials Section 5 Figure 1).

The importance of all predictors in the MARS LST downscaling models was indicated by the frequency of use of each predictor in the basis functions forming model equations (Supplementary materials Section 4 Table 4) in $\mathrm{MARS}_{2 / 4 \mathrm{ma}}$ models. All input predictors were consistently used 0 to 5 times in each model developed for each town and each date composed, which highlighted the importance of consideration of multiple predictors in LST downscaling models as each factor may carry useful information in different areas of the data feature space.

\section{Performance of LST downscaling models}

The performance of $\mathrm{MARS}_{2 / 4 \mathrm{ma}}$ models used to downscale LST from a medium spatial resolution (100m) to very high spatial resolution (2 to $4 \mathrm{~m})$ was assessed by the adjusted $\mathrm{R}^{2}$ metric returned by the models at the model development stage as well as 
root mean square errors calculated between the downscaled and observed values. Adjusted $\mathrm{R}^{2}$ values (Supplementary Materials Section 5 Table 1) reveal that models developed for summer months had a stronger predictive power than models developed for winter months, with the adjusted $\mathrm{R}^{2}$ ranging between 0.64 to 0.84 for summer and 0.06 to 0.21 for winter, depending on town and date. In the summer, the highest model performance was obtained for Luton, for which the effective spatial resolution of all high resolution spectral indices was $4 \mathrm{~m}$, which decreased the scale effect between the observed and target resolutions (Zhou et al. 2016) from 50 to 25. Otherwise, it could be assumed that the $\mathrm{MARS}_{2 / 4 \mathrm{ma}}$ models can explain 65 to $70 \%$ of the variance in LST when the majority of predictors is derived at $2 \mathrm{~m}$ resolution. Poor model performance in winter, however, could be explained by lower dependence of LST on the differences in land cover due to reduced development of foliage as well as potential importance of anthropogenic sources of heat, such as heating of buildings, that were not captured by spectral response of imagery in visible to shortwave infrared regions of the light spectra, from which the spectral indices used in this study were derived. The satellite-derived LST images for the winter dates were also affected by striping, caused by the stray light error of the Landsat 8 thermal bands (Montanaro et al. 2014), and these artefacts likely weakened the relationship between LST and LST predictors used in this study, making the model performance results obtained for winter inconclusive.

Root mean square errors (RMSE) calculated for the unprocessed downscaled maps (Table 2) confirmed the observations based on the adjusted $\mathrm{R}^{2}$ values that, in the summer, MARS 2/4 madels had the highest performance, and that adjusting procedure of the high-resolution spectral indices for the values of equivalent satellitederived indices to correct for the temporal mismatch between collection dates of the aerial and satellite imagery was highly effective in enhancing the accuracy of the 
downscaled LST maps, yielding an improvement in the range of 0.62 to $1.27 \mathrm{~K}$ depending on town and date. In winter, the RMSE ranged between $0.44-0.63 \mathrm{~K}$ across all three towns and did not vary with the modelling approach, confirming poor predictive power of these models.

Table 2 RMSE calculated for the pairs of observed and downscaled LST values: A) unprocessed downscaled maps obtained with the $\mathrm{MARS}_{2 / 4 \mathrm{ma}}$ models and B) downscaled maps obtained with the $\mathrm{MARS}_{2 / 4 \mathrm{ma}}$ models with added residuals. The Ratio columns specify the value of the ratio calculated between the RMSE and standard deviation of the observed LST values for each town and date.

\begin{tabular}{ccccccc}
\hline \multirow{2}{*}{$\begin{array}{c}\boldsymbol{7} \text { Unprocessed downscaled maps } \\
\text { Town }\end{array}$} & \multicolumn{7}{c}{ Bedford } & \multicolumn{5}{c}{ Luton } \\
\cline { 2 - 7 } Method & MARSadj & Ratio & MARSadj & Ratio & MARSadj & Ratio \\
\hline FEB & 0.44 & 0.88 & 0.52 & 1.04 & 0.57 & 0.95 \\
JAN & 0.45 & 0.90 & 0.61 & 1.02 & 0.62 & 1.03 \\
JUN & 1.83 & 0.52 & 1.44 & 0.42 & 1.78 & 0.59 \\
JUL & 1.72 & 0.59 & 1.40 & 0.39 & 1.54 & 0.59 \\
\hline \multicolumn{7}{c}{ Downscaled maps adjusted for residuals } \\
\hline B & \multicolumn{7}{c}{ Luton } \\
Town & \multicolumn{7}{c}{ Bedford } \\
Method & MARSadj & Ratio & MARSadj & Ratio & MARSadj & Ratio \\
\hline FEB & 0.13 & 0.26 & 0.08 & 0.16 & 0.13 & 0.22 \\
JAN & 0.07 & 0.14 & 0.17 & 0.28 & 0.09 & 0.15 \\
JUN & 1.21 & 0.35 & 0.76 & 0.22 & 1.08 & 0.36 \\
JUL & 1.18 & 0.41 & 0.84 & 0.23 & 0.96 & 0.37 \\
\hline
\end{tabular}

between RMSE and standard derivation of reference LST data (in our case the satellitederived LST), for which values close to 1 indicate low model performance (Bonafoni and Tosi, 2017). These confirmed low model performance for winter images, and indicated that models derived for summer had fair performance. After correction for the residuals, both the RMSE and the RMSE to LST standard deviation ratios dropped considerably, especially for winter images. In the summer, a degree of error persisted somewhat even after the correction, indicating that the downscaling approach did not capture all of the underlying variability of LST at the very high resolution. 
Further insight into the performance of the downscaling models is offered by LST density plots (Supplementary Materials Section 5 Figure 1) that allow for comparisons of the distributions of the observed and modelled LST values across the entire range of possible values. These plots indicated that the RMSE values in the unprocessed MARS $_{2 / 4 \mathrm{ma}}$ maps derived for summer are largely driven by misrepresentation of the extreme observed LST values and that this method yielded good resemblance of the distributions of the most frequent values in the observed LST images. These plots also confirmed the superiority of the $\mathrm{MARS}_{2 / 4 \mathrm{ma}}$ method over multiple regression models, derived with the same set of LST predictors, which misrepresented the distribution of both the mid-range and extreme LST values, as well as the importance of the correction of temporal mismatch between the capture dates of the aerial and satellite imagery affecting the fine resolution spectral indices used in LST downscaling. The plots also confirmed that all models derived for winter predicted values close to the mean of observed LST values and did not capture the range of variation in the observed LST.

\section{LST mapping at medium and very high spatial resolution}

Visual assessment of the downscaled maps (Figure and 5) reveals that the main LST patterns as seen in the satellite-derived images were well reflected in the downscaled images, especially in the summer, and that these correspond well with the locations of the main types of land cover, with vegetated areas being typically cooler than paved. In winter, the LST variation of the downscaled maps did not match the observed patterns just as well and only major differences due to occurrence of water bodies or built-up areas were marked in the modelled maps. Another difference between the observed and downscaled LST images is that the latter appear not to have represented the warmest and coolest areas of the satellite-derived maps correctly. These findings are reflected in standard deviations of the downscaled LST maps 
(Supplementary Materials Section 6 Tables 1 and 2), which are lower than in the observed images, especially for winter $(0.1-0.2 \mathrm{~K}$ as opposed to $0.5-0.6 \mathrm{~K})$, whereas for the summer are closer in magnitude to the observed values $(2.1-3.3 \mathrm{~K}$ as compared to $2.6-3.6 \mathrm{~K})$. The downscaled maps, however, have an advantage over the satellitederived images in that they do pick out the detail of urban fabric, including the outlines of individual buildings, paved and green spaces (refer to Figure 2 in Section 6 of Supplementary Materials), making them suitable for urban thermal environment studies at much needed local scales 


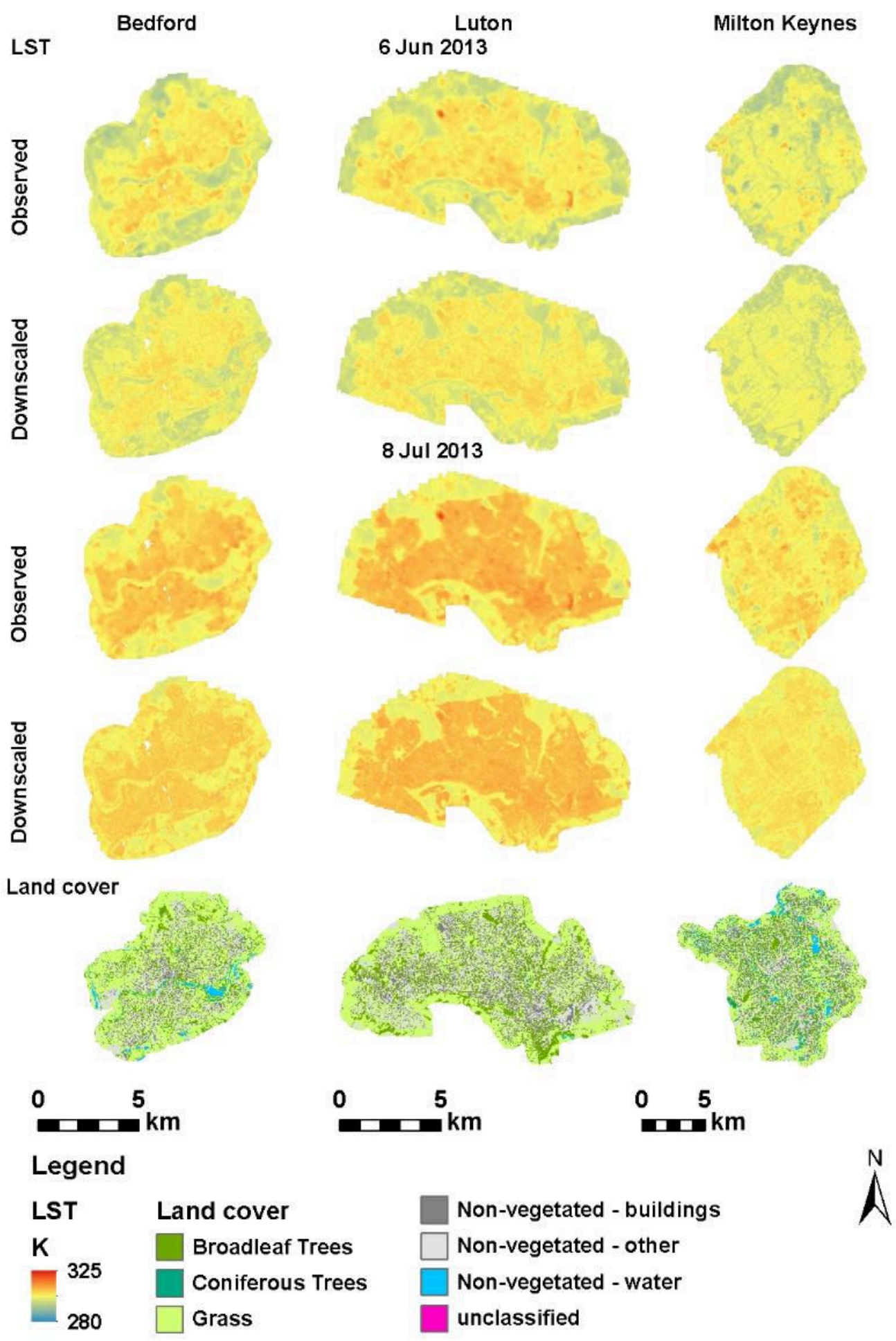

Figure 4 Comparison of satellite-derived (observed) and downscaled LST images derived with the $\mathrm{MARS}_{2 / 4 \mathrm{ma}}$ models constructed with adjusted spectral indices at 2 to $4 \mathrm{~m}$ spatial resolution for Bedford, Luton and Milton Keynes derived for summer dates. Land cover maps are shown for comparison of LST with the patterns of urban fabric. 


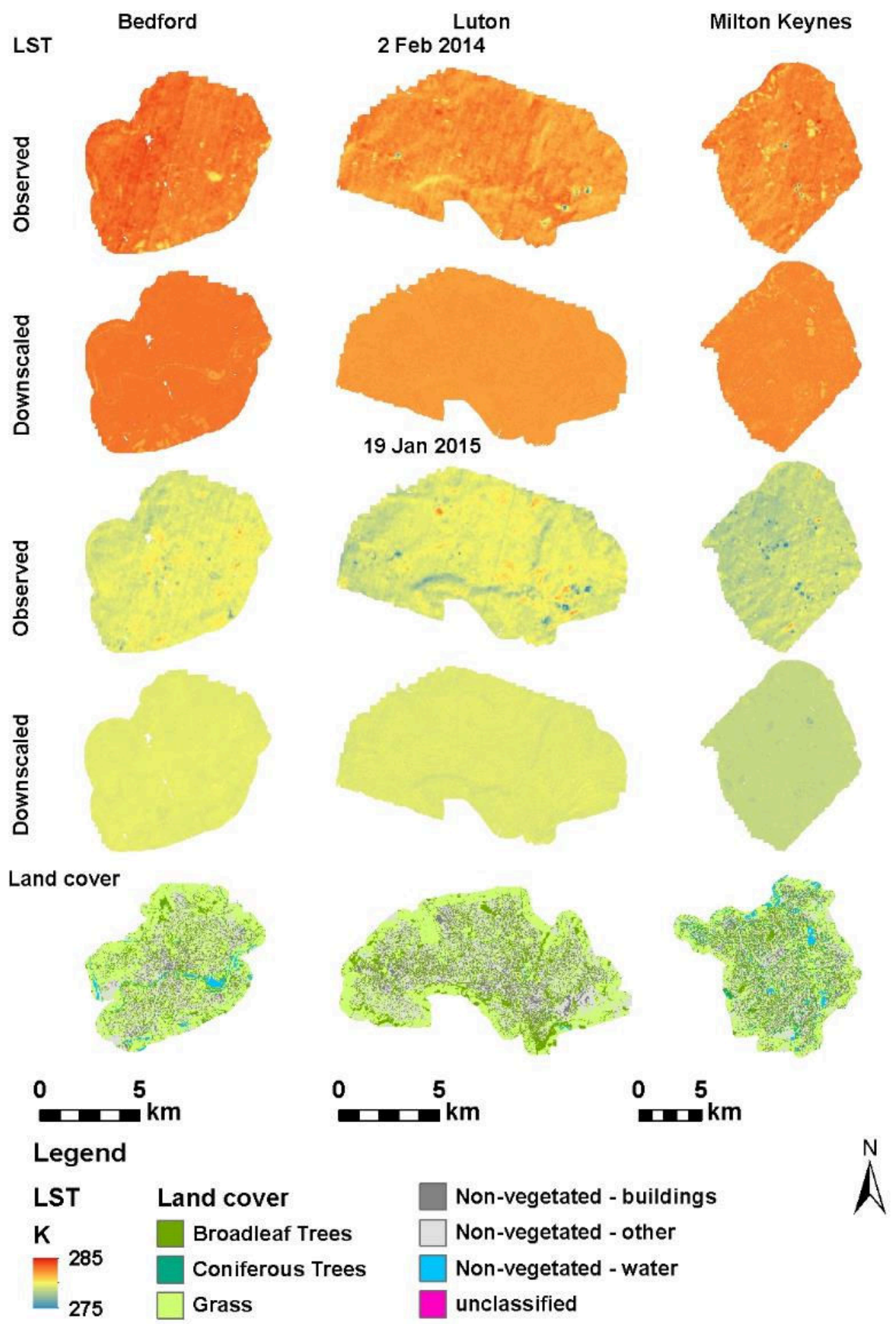

Figure 5 Comparison of satellite-derived (observed) and downscaled LST images derived with the $\mathrm{MARS}_{2 / 4 \mathrm{ma}}$ models constructed with adjusted spectral indices at 2 to $4 \mathrm{~m}$ spatial resolution for Bedford, Luton and Milton Keynes derived for winter dates. Land cover maps are shown for comparison of LST with the patterns of urban fabric. 


\section{Discussion}

The primary goal of this study was to generate very high spatial resolution LST maps for urban areas based on medium spatial resolution satellite observations and very high resolution auxiliary data. Our target spatial resolution of 2 to $4 \mathrm{~m}$ was driven by the spatial resolution of the available ancillary hyperspectral aerial imagery, which was $2 \mathrm{~m}$ for the visible and near infrared, and $4 \mathrm{~m}$ for the short wave infrared spectra. Given that our LST downscaling approach was based on observed LST at 100m resolution, the downscaling factor, defined as the ratio between the observed and downscaled spatial resolution (Zhou et al., 2016; Bonafoni and Tosi, 2017), was at an unprecedented 25/50. The downscaling factor has its implications on the accuracy of the downscaled maps, measured by RMSE, with larger differences between the source and target resolutions resulting in lower accuracies of the downscaled images. This could be partially explained by the scale effect and the assumption of conditionality of the scale-invariant relationship between LST and its descriptors (Zhou et al. 2016). Temperatures over the land surface can vary strongly and abruptly over space (Prata et al. 1995), and this variation can be lost at spatial resolution of satellite TIR sensors. Indeed, Agam et al. (2007) attributed the increasing RMSE of downscaled LST maps with the increasing downscaling factor due to the increased variability of LST values at higher as compared to lower spatial resolutions. This poses a practical difficulty for the development of downscaling models in the extreme LST ranges of fine resolution LST values due to the lack or low availability of data pixels characterised with such values at coarser

resolutions (Liu and Pu, 2008; Mukherjee et al., 2015b; Hutengs and Vohland, 2016) regardless of the implemented downscaling method.

Despite the high downscaling factor, the RMSE resulting from our approach for the summer dates was comparable or lower than RMSEs found in the other published urban 
studies, although it has to be noted that all studies listed below either used independent LST maps to validate their downscaling results or developed their downscaling models on upscaled LST data and verified the result with the original dataset, which limits comparability of our assessments. For example, spectral unmixing method applied by Deng and $\mathrm{Wu}$ (2013) to downscale a Landsat TM image down to 4m spatial resolution yielded with RMSE of 2K, and Bonafoni and Tosi (2017), achieved RMSE of 2.96, 2.85 , and $2.71 \mathrm{~K}$ when using the same principle to downscale LST at $40 \mathrm{~m}, 30 \mathrm{~m}$, and $20 \mathrm{~m}$ to $2 \mathrm{~m}$ in an urban environment. Other urban LST studies, pertaining to coarser resolutions of output LST maps and scaling factors ranging from 2 to 12 as well as application of various LST downscaling methods, achieved RMSE ranging between 1.28 and 3.9K (Yang et al., 2010; Zhan et al., 2012; Keramitsoglou and Kiranoudis, 2013; Weng and Fu, 2014; Bonafoni, 2016; Yang et al., 2017). In winter, however, the low effectiveness of the downscaling method could have resulted from poor correlation between spectral indices and the reduced ranges of observed LST as compared to summer. This is consistent with lower correlations between the Urban Impervious Surface index in winter than summer LST observed in a selection of Chinese urban areas (Ma et al., 2016) as well as lower performance of LST downscaling procedure observed by (Yang et al. 2017) explained by worse performance of such methods when LST magnitudes are lower or when the values of LST are altered by ice and snow cover. Another explanation for poor performance of our downscaling approach in winter could be the previously mentioned stray light error affecting the Landsat 8 thermal sensors and resulting with discernible ghosting within LST maps generated from the TIR bands. In our data this problem was especially visible in the winter-time LST maps, which in turn would have introduced noise into MARS models constructed for the winter scenes, lowering their overall accuracy. 
The accuracy of the downscaled LST maps can also depend on the downscaling process (Zhou et al. 2016) which includes the type and number of selected LST descriptors and the applied regression method (Zhan et al. 2013). We chose to use a combination of previously utilised spectral indices, such as NDVI and NDBI as well as land cover fraction within pixels coupled with indices not utilised in previous studies (CMR, FMR and IOR). Our results suggested that in urban areas dominated by a mosaic of vegetated, paved and built-up spaces, NDBI and FMR next to NDVI can be important as LST predictors in downscaling studies, especially in the summer. This finding is consistent with other studies that used NDBI alongside NDVI and other spectral indices as a downscaling factor and obtained reduced RMSE as compared to methods using solely NDVI (Bonafoni et al. 2016). Good performance of FMR can be explained by the fact that, similarly to NDBI, it is composed of a ratio between short-wave and nearinfrared bands, that have been shown to contribute to higher performance of LST downscaling procedure using random forests presented in Hutengs and Vohland (2016). Combination of multiple LST predictors contributed to lowering of RSME, which is consistent with many other LST downscaling studies (Yang et al., 2010; Hutengs and Vohland, 2016; Bonafoni and Tosi, 2017) where the use of several LST predictors showed improvement over the standard methods of DisTrad (Kustas et al. 2003) or TsHARP (Agam et al., 2007) utilising NDVI as the sole input. In our case study, the MARS method confirmed findings of other LST downscaling studies that using nonlinear regression methods such as artificial neural networks (Kolios, Georgoulas, and Stylios 2013) or random forests (Hutengs and Vohland 2016) can reduce the RMSE of the downscaled map as compared to multiple regression methods, when coupled with multiple LST predictors. 
We also implemented a novel method for making adjustments for the temporal mismatch between available LST data at a coarse spatial resolution and very high resolution LST downscaling factors by adjusting the values of very high spatial resolution spectral indices for the values of equivalent coarse resolution spectral indices derived for the target dates by means of spatial interpolation of differences between images in question. Typically, in LST downscaling studies, spectral indices used as downscaling factors and LST data are derived from temporally matching datasets (Kustas et al., 2003; Agam et al., 2007; Yang et al., 2010; Mukherjee et al., 2014). As so far, Bonafoni et al. (2016) addressed the temporal mismatch between Landsat-derived and airborne LST maps by averaging the Landsat-derived LST captured on the closest possible dates before and after the acquisition date of the airborne LST image. This, however, was carried out for validation rather than LST-downscaling purposes and was only possible due to seasonal similarity of all the images. Using spectral information captured at various dates to fill in missing spectral information at a date of interest is not uncommon in remote sensing and can be, for instance, implemented for the purpose of cloud cover and cloud shadow correction. This can be done by replacing the missing information within one image with spectral information of another with the application of image fusion within transition zones to account for differences in image colour (Tseng, Tseng, and Chien 2008), information cloning whereby temporal correlation of multitemporal images is utilised to fill in the gaps (Lin et al. 2013), or by contextual reconstruction of cloud-contaminated multitemporal images by reproduction of local spectro-temporal relationships between the considered image and a opportunely selected subset of remaining temporal images (Melgani 2006). Our method of spectral indices adjustment allows for application of LST downscaling for multiple dates without the 
necessity of repeated acquisition of very high resolution multispectral imagery, at least for seasons with developed green vegetation.

\section{Conclusions}

The main objective of this study was to generate very high resolution land surface temperature maps for three English towns, Milton Keynes, Bedford and Luton, suitable for determination of the local temperature regulation ecosystem service of urban greenspaces. We applied the multivariate adaptive regression splines method to downscale LST derived from 100m resolution satellite thermal images down to 2 to $4 \mathrm{~m}$ spatial resolution, with the use of spectral indices derived from high resolution aerial imagery as well as fractional cover of paved and water surfaces, achieving satisfactory results for images captured in the summer and poor performance for winter-time images. The proposed novel technique for addressing non-matching dates of satellite and aerial imagery used in LST downscaling, consisting of adjusting the spectral indices derived from aerial imagery for kriged residuals calculated from the comparison to equivalent spectral indices derived from the reference satellite imagery, performed satisfactorily and contributed to increased model performance statistics for months with developed vegetation cover. We confirmed that inclusion of multiple spectral indices, and especially ones that are composed of the NIR and SWIR wavebands, can improve the accuracy of the downscaled LST maps. Further improvements to the proposed methodology could involve enhancements to the adjusting procedure of very high resolution spectral indices for the values of equivalent coarse resolution indices derived for the dates of interest as well as incorporation of additional land surface temperature indicators capable of explaining portions of the spatial variation of LST that cannot be represented by spectral indices, such as maps of anthropogenic sources of high or low heat areas. 
Acknowledgements

This research (Grant Number NE/ J015067/1) was conducted as part of the Fragments, Functions and Flows in Urban Ecosystem Services (F3UES) project as part of the larger Biodiversity and Ecosystem Service Sustainability (BESS) framework. BESS is a six-year programme (2011-2017) funded by the UK Natural Environment Research Council (NERC) and the Biotechnology and Biological Sciences Research Council (BBSRC) as part of the UK's Living with Environmental Change (LWEC) programme. This work presents the outcomes of independent research funded by NERC and the BESS programme, and the views expressed are those of the authors and not necessarily those of the BESS Directorate or NERC.

We would also like to thank Professor Phil Warren, Dr Karl Evans and Dr Briony Norton for initiating the idea of the presented work as well as invaluable discussions shaping the form of this manuscript; and Dr Steven Hancock for his support in processing of the aerial imagery.

The supplemental material for this paper is available at XXXXX 


\section{References:}

Agam, Nurit, William P. Kustas, Martha C. Anderson, Fuqin Li, and Christopher M.U. Neale. 2007a. "A Vegetation Index Based Technique for Spatial Sharpening of Thermal Imagery." Remote Sensing of Environment 107 (4): 545-558. doi:10.1016/j.rse.2006.10.006.

Asgarian, Ali, Bahman Jabbarian Amiri, and Yousef Sakieh. 2015. "Assessing the Effect of Green Cover Spatial Patterns on Urban Land Surface Temperature Using Landscape Metrics Approach." Urban Ecosystems 18 (1). Springer US: 209-222. doi:10.1007/s11252-014-0387-7.

Bonafoni, Stefania. 2016. "Downscaling of Landsat and MODIS Land Surface Temperature over the Heterogeneous Urban Area of Milan.” IEEE Journal of Selected Topics in Applied Earth Observations and Remote Sensing 9 (5): 20192027. doi:10.1109/JSTARS.2016.2514367.

Bonafoni, Stefania, Roberta Anniballe, Beniamino Gioli, and Piero Toscano. 2016. "Downscaling Landsat Land Surface Temperature over the Urban Area of Florence." European Journal of Remote Sensing 49 (1). Taylor \& Francis: 553569. doi:10.5721/EuJRS20164929.

Bonafoni, Stefania, and Grazia Tosi. 2017. "Downscaling of Land Surface Temperature Using Airborne High-Resolution Data : A Case Study on Aprilia , Italy.” IEEE Geoscience and Remote Sensing Letter 14 (1): 107-111. doi:10.1109/LGRS.2016.2630798.

Bornstein, Robert D. 1968. "Observations of the Urban Heat Island Effect in New York City." Journal of Applied Meteorology 7 (4): 575-582. doi:10.1175/15200450(1968)007<0575:OOTUHI>2.0.CO;2.

Cressie, Noel. 1988. "Spatial Prediction and Ordinary Kriging.” Mathematical Geology 20 (4). Kluwer Academic Publishers-Plenum Publishers: 405-421. doi:10.1007/BF00892986.

Deng, Chengbin, and Changshan Wu. 2013. "Estimating Very High Resolution Urban Surface Temperature Using a Spectral Unmixing and Thermal Mixing Approach." International Journal of Applied Earth Observation and Geoinformation 23 (1): 155-164. doi:10.1016/j.jag.2013.01.001.

Feng, Xiao, Giles Foody, Paul Aplin, and Simon N. Gosling. 2015. "Enhancing the Spatial Resolution of Satellite-Derived Land Surface Temperature Mapping for 
Urban Areas." Sustainable Cities and Society 19: 341-348.

doi:10.1016/j.scs.2015.04.007.

Friedman, Jerome H. 1991. "Multivariate Adaptive Regression Splines.” The Annals of Statistics 19 (1). Institute of Mathematical Statistics: 1-67. doi:10.1214/aos/1176347963.

Grafius, D.R., R. Corstanje, P.H. Warren, K.L. Evans, S. Hancock, and J.A. Harris. 2016. "The Impact of Land Use/Land Cover Scale on Modelling Urban Ecosystem Services.” Landscape Ecology 31 (7). doi:10.1007/s10980-015-03377.

Grafius, Darren R., Ron Corstanje, Gavin M. Siriwardena, Kate E. Plummer, and Jim A. Harris. 2017. “A Bird's Eye View: Using Circuit Theory to Study Urban Landscape Connectivity for Birds." Landscape Ecology 32 (9). Springer Netherlands: 1771-1787. doi:10.1007/s10980-017-0548-1.

Hutengs, Christopher, and Michael Vohland. 2016. "Downscaling Land Surface Temperatures at Regional Scales with Random Forest Regression.” Remote Sensing of Environment 178: 127-141. doi:10.1016/j.rse.2016.03.006.

Jenerette, G. Darrel, Sharon L. Harlan, Alexander Buyantuev, William L. Stefanov, Juan Declet-Barreto, Benjamin L. Ruddell, Soe Win Myint, Shai Kaplan, and Xiaoxiao Li. 2015. "Micro-Scale Urban Surface Temperatures Are Related to Land-Cover Features and Residential Heat Related Health Impacts in Phoenix, AZ USA." Landscape Ecology, October. Kluwer Academic Publishers. doi:10.1007/s10980-015-0284-3.

Jimenez-Munoz, Juan C., Jose A. Sobrino, Drazen Skokovic, Cristian Mattar, and Jordi Cristobal. 2014. "Land Surface Temperature Retrieval Methods from Landsat-8 Thermal Infrared Sensor Data.” IEEE Geoscience and Remote Sensing Letters 11 (10). IEEE: 1840-1843. doi:10.1109/LGRS.2014.2312032.

Kalkstein, L. S., and K. E. Smoyer. 1993. "The Impact of Climate Change on Human Health: Some International Implications.” Experientia 49 (11): 969-979. doi:10.1007/BF02125644.

Keramitsoglou, I., and C. T. Kiranoudis. 2013. "Downscaling Geostationary Land Surface Temperature Imagery for Urban Analysis.” IEEE Geoscience and Remote Sensing Letters 10 (5): 1253-1257. doi:10.1109/LGRS.2013.2257668. 
Kolios, Stavros, George Georgoulas, and Chrysostomos Stylios. 2013. “Achieving Downscaling of Meteosat Thermal Infrared Imagery Using Artificial Neural Networks.” International Journal of Remote Sensing 34 (21): 7706-7722. doi:10.1080/01431161.2013.825384.

Kong, Fanhua, Haiwei Yin, Philip James, Lucy R. Hutyra, and Hong S. He. 2014.

"Effects of Spatial Pattern of Greenspace on Urban Cooling in a Large Metropolitan Area of Eastern China." Landscape and Urban Planning 128 (August): 35-47. doi:10.1016/j.landurbplan.2014.04.018.

Kustas, William P., John M. Norman, Martha C. Anderson, and Andrew N. French. 2003. "Estimating Subpixel Surface Temperatures and Energy Fluxes from the Vegetation Index-radiometric Temperature Relationship.” Remote Sensing of Environment 85 (4): 429-440. doi:10.1016/S0034-4257(03)00036-1.

Lee, Sang-Mi, Harindra J.S. Fernando, Marko Princevac, Dragan Zajic, Michela Sinesi, Jennifer L. McCulley, and James Anderson. 2003. "Transport and Diffusion of Ozone in the Nocturnal and Morning Planetary Boundary Layer of the Phoenix Valley." Environmental Fluid Mechanics 3 (4). Kluwer Academic Publishers: 331-362. doi:10.1023/A:1023680216173.

Lin, Chao-Hung, Po-Hung Tsai, Kang-Hua Lai, and Jyun-Yuan Chen. 2013. "Cloud Removal From Multitemporal Satellite Images Using Information Cloning." IEEE Transactions on Geoscience and Remote Sensing 51 (1): 232-241. doi:10.1109/TGRS.2012.2197682.

Liu, Desheng, and Ruiliang Pu. 2008. "Downscaling Thermal Infrared Radiance for Subpixel Land Surface Temperature Retrieval.” Sensors 8 (4): 2695-2706. doi:10.3390/s8042695.

Lo, C. P., D. A. Quattrochi, and J. C. Luvall. 1997. “Application of High-Resolution Thermal Infrared Remote Sensing and GIS to Assess the Urban Heat Island Effect.” International Journal of Remote Sensing 18 (2). Taylor \& Francis Group: 287-304. doi:10.1080/014311697219079.

Ma, Qun, Jianguo Wu, and Chunyang He. 2016. "A Hierarchical Analysis of the Relationship between Urban Impervious Surfaces and Land Surface Temperatures: Spatial Scale Dependence, Temporal Variations, and Bioclimatic Modulation.” Landscape Ecology 31 (5). Springer Netherlands: 1139-1153. doi:10.1007/s10980-016-0356-z. 
Melgani, F. 2006. "Contextual Reconstruction of Cloud-Contaminated Multitemporal Multispectral Images." IEEE Transactions on Geoscience and Remote Sensing 44 (2): 442-455. doi:10.1109/TGRS.2005.861929.

Montanaro, Matthew, Aaron Gerace, Allen Lunsford, Dennis Reuter, Matthew Montanaro, Aaron Gerace, Allen Lunsford, and Dennis Reuter. 2014. "Stray

Light Artifacts in Imagery from the Landsat 8 Thermal Infrared Sensor.” Remote Sensing 6 (11). Multidisciplinary Digital Publishing Institute: 10435-10456. doi:10.3390/rs61110435.

Mukherjee, Sandip, P.K. Joshi, and R.D. Garg. 2014. "A Comparison of Different Regression Models for Downscaling Landsat and MODIS Land Surface Temperature Images over Heterogeneous Landscape.” Advances in Space Research 54 (4): 655-669. doi:10.1016/j.asr.2014.04.013.

Mukherjee, Sandip, P.K. Joshi, and Rahul D. Garg. 2015a. "Evaluation of LST Downscaling Algorithms on Seasonal Thermal Data in Humid Subtropical Regions of India.” International Journal of Remote Sensing, May. Taylor \& Francis. http://www.tandfonline.com/doi/abs/10.1080/01431161.2015.1041175. Norton, Briony A., Andrew M. Coutts, Stephen J. Livesley, Richard J. Harris, Annie M. Hunter, and Nicholas S.G. Williams. 2015. "Planning for Cooler Cities: A Framework to Prioritise Green Infrastructure to Mitigate High Temperatures in Urban Landscapes." Landscape and Urban Planning 134 (February): 127-138. doi:10.1016/j.landurbplan.2014.10.018.

Odeh, I. O.A., A. B. McBratney, and D. J. Chittleborough. 1995. "Further Results on Prediction of Soil Properties from Terrain Attributes: Heterotopic Cokriging and Regression-Kriging." Geoderma 67 (3-4). Elsevier: 215-226. doi:10.1016/0016-7061(95)00007-B.

Piikki, K., J. Wetterlind, M. Söderström, and B. Stenberg. 2014. “Three-Dimensional Digital Soil Mapping of Agricultural Fields by Integration of Multiple Proximal Sensor Data Obtained from Different Sensing Methods." Precision Agriculture 16 (1). Springer US: 29-45. doi:10.1007/s11119-014-9381-6.

Piikki, Kristin, and Mats Söderström. 2017. "Digital Soil Mapping of Arable Land in Sweden - Validation of Performance at Multiple Scales." Geoderma, November 3. doi:10.1016/j.geoderma.2017.10.049. 
Pitman, Sheryn D, Christopher B Daniels, and Martin E Ely. 2015. "Green

Infrastructure as Life Support: Urban Nature and Climate Change."

Transactions of the Royal Society of South Australia 139 (1). Taylor \& Francis: 97-112. doi:10.1080/03721426.2015.1035219.

Prata, A. J., V. Caselles, C. Coll, J. A. Sobrino, and C. Ottlé. 1995. "Thermal Remote Sensing of Land Surface Temperature from Satellites: Current Status and Future Prospects.” Remote Sensing Reviews 12 (3-4). Taylor \& Francis Group : 175224. doi:10.1080/02757259509532285.

Sanusi, Ruzana, Denise Johnstone, Peter May, and Stephen J Livesley. 2016. "Street Orientation and Side of the Street Greatly Influence the Microclimatic Benefits Street Trees Can Provide in Summer.” Journal of Environmental Quality 45 (1). The American Society of Agronomy, Crop Science Society of America, and Soil Science Society of America, Inc.: 167-174. doi:10.2134/jeq2015.01.0039.

Shochat, Eyal, Paige S Warren, Stanley H Faeth, Nancy E McIntyre, and Diane Hope. 2006. "From Patterns to Emerging Processes in Mechanistic Urban Ecology." Trends in Ecology \& Evolution 21 (4). Elsevier: 186-191. doi:10.1016/j.tree.2005.11.019.

Sobrino, José A., Juan C. Jiménez-Muñoz, Guillem Sòria, Mireia Romaguera, Luis Guanter, José Moreno, Antonio Plaza, and Pablo Martínez. 2008. "Land Surface Emissivity Retrieval from Different VNIR and TIR Sensors.” In , 46:316-327. doi:10.1109/TGRS.2007.904834.

Takebayashi, Hideki. 2017. "Influence of Urban Green Area on Air Temperature of Surrounding Built-Up Area.” Climate 5 (3). Multidisciplinary Digital Publishing Institute: 60. doi:10.3390/cli5030060.

Tseng, Din-Chang, Hsiao-Ting Tseng, and Chun-Liang Chien. 2008. “Automatic Cloud Removal from Multi-Temporal SPOT Images." Applied Mathematics and Computation 205 (2). Elsevier: 584-600. doi:10.1016/J.AMC.2008.05.050.

United Nations, Department of Economic and Social Affairs, Population Division.2018. "World Urbanization Prospects: The 2018 Revision, Online Edition." Available from https://esa.un.org/unpd/wup/ Publications.

Wang, Liang-Jie, Min Guo, Kazuhide Sawada, Jie Lin, and Jinchi Zhang. 2015. "Landslide Susceptibility Mapping in Mizunami City, Japan: A Comparison between Logistic Regression, Bivariate Statistical Analysis and Multivariate 
Adaptive Regression Spline Models.” CATENA 135 (December). Elsevier: 271282. doi:10.1016/J.CATENA.2015.08.007.

Weng, Qihao, and Peng Fu. 2014. "Modeling Diurnal Land Temperature Cycles over Los Angeles Using Downscaled GOES Imagery." ISPRS Journal of Photogrammetry and Remote Sensing 97 (November): 78-88. doi:10.1016/j.isprsjprs.2014.08.009.

Yang, Guijun, Ruiliang Pu, Wenjiang Huang, Jihua Wang, and Chunjiang Zhao. 2010. "A Novel Method to Estimate Subpixel Temperature by Fusing Solar-Reflective and Thermal-Infrared Remote-Sensing Data With an Artificial Neural Network." IEEE Transactions on Geoscience and Remote Sensing 48 (4): 2170-2178. doi:10.1109/TGRS.2009.2033180.

Yu, Chen, and Wong Nyuk Hien. 2006. “Thermal Benefits of City Parks.” Energy and Buildings 38 (2). Elsevier: 105-120. doi:10.1016/J.ENBUILD.2005.04.003.

Yang, Yingbao, Xiaolong Li, Xin Pan, Yong Zhang, and Chen Cao. 2017.

"Downscaling Land Surface Temperature in Complex Regions by Using Multiple Scale Factors with Adaptive Thresholds." Sensors (Switzerland) 17 (4). Multidisciplinary Digital Publishing Institute: 744. doi:10.3390/s17040744.

Zhan, Wenfeng, Yunhao Chen, Jinfei Wang, Ji Zhou, Jinling Quan, Wenyu Liu, and Jing Li. 2012. "Downscaling Land Surface Temperatures with Multi-Spectral and Multi-Resolution Images." International Journal of Applied Earth Observation and Geoinformation 18 (1): 23-36. doi:10.1016/j.jag.2012.01.003.

Zhan, Wenfeng, Yunhao Chen, Ji Zhou, Jinfei Wang, Wenyu Liu, James Voogt, Xiaolin Zhu, Jinling Quan, and Jing Li. 2013. “Disaggregation of Remotely Sensed Land Surface Temperature: Literature Survey, Taxonomy, Issues, and Caveats.” Remote Sensing of Environment.

Zhou, Ji, Shaomin Liu, Mingsong Li, Wenfeng Zhan, Ziwei Xu, and Tongren Xu. 2016. "Quantification of the Scale Effect in Downscaling Remotely Sensed Land Surface Temperature.” Remote Sensing 8 (12). Multidisciplinary Digital Publishing Institute: 975. doi:10.3390/rs8120975.

Zhou, Weiqi, Jia Wang, and Mary L. Cadenasso. 2017. "Effects of the Spatial Configuration of Trees on Urban Heat Mitigation: A Comparative Study." Remote Sensing of Environment 195 (June). Elsevier: 1-12. doi:10.1016/j.rse.2017.03.043. 


\section{Section 1 Methodology for land surface temperature mapping at medium}

spatial resolution from Landsat 8 thermal data.

Emissivity for bands 10 and 11 of Landsat 8 sensor was estimated using the NDVI thresholds method that involves the assignment of emissivity values for different types of land cover based on NDVI values obtained from red and near-infrared bands of satellite images of the study area. Typically, NDVI is used to determine the locations of bare ground and fully vegetated areas, to which respective emissivity values are assigned. The intermediary emissivity values are calculated from predefined equations, taking into the account the vegetation fraction within a given pixel. In this study we used the simplified NDVI thresholds method, as presented in Sobrino et al. (2008), with a modification to allow for the assignment of emissivity values for pixels occupied by water as well as built-up areas rather than soil (Equation 1). Based on visual inspection of the available imagery, NDVI threshold for water-occupied pixels was set to $\leq-$ 0.0001 , built-up pixels to the range between -0.0001 and 0.05 , and purely vegetated pixels to $>0.5$. Emissivity values for the pure land cover pixels were calculated as averages of data supplied by the MODIS UCSB Emissivity Library (https://icess.eri.ucsb.edu/modis/EMIS/html/em.html) for wavelengths equivalent to the thermal bands of Landsat 8 . The emissivity for built-up areas was calculated as a mean of corresponding emissivity measurements for asphalt and apache interlocking pavement ( 0.973 and 0.965 respectively for bands 10 and 11$)$, the emissivity for vegetation as a mean for oak and pine trees $(0.976$ and 0.975$)$, and for water as a mean of values provided for water (0.987 and 0.992). Emissivity layers were derived from NDVI calculated at a $30 \mathrm{~m}$ resolution from Landsat 8 imagery acquired for each date considered in this study. Subsequently, the mean and difference between emissivity for band 10 and 11 were calculated. The resulting layers at $30 \mathrm{~m}$ resolution were sharper 
than the thermal bands of the Landsat 8 , which were captured at $100 \mathrm{~m}$ resolution and subsequently resampled to $30 \mathrm{~m}$ by the data provider, and therefore mismatching the thermal information available from Landsat 8. In order to mitigate this mismatch we have upscaled the $30 \mathrm{~m}$ resolution emissivity mean and difference layers by first resampling them to $10 \mathrm{~m}$ with the nearest neighbour method retaining the $30 \mathrm{~m}$ pixel values, then aggregating to $100 \mathrm{~m}$ resolution with a mean function, and finally resampling back to $30 \mathrm{~m}$ resolution with the bilinear convolution method to match the processing method of Landsat 8 TIR bands.

$$
\varepsilon_{i, j}=\left\{\begin{array}{c}
\varepsilon_{w}, N D V I \leq N D V I_{w} \\
\varepsilon_{b i, j}, N D V I_{w} \leq N D V I \leq N D V I_{b} \\
\varepsilon_{b i, j}+\left(\varepsilon_{v i, j}-\varepsilon_{b i, j}\right) P_{v}, N D V I_{b} \leq N D V I \leq N D V I_{v} \\
\varepsilon_{v i, j}, N D V I>N D V I_{v}
\end{array}\right.
$$

Where:

$\varepsilon_{i, j}-$ emissivity for bands $i$ and $j$;

$\varepsilon_{w i, j}-$ emissivity value for water for bands $i$ and $j$, obtained from spectral libraries;

$\varepsilon_{b i, j}$ - emissivity value for built-up areas for bands $i$ and $j$, obtained from spectral libraries;

$\varepsilon_{v i, j}-$ emissivity value for vegetation for bands $i$ and $j$, obtained from spectral libraries;

NDVI - NDVI pixel value at a given location;

$N D V I_{b}-\mathrm{NDVI}$ threshold value for built-up areas;

$N D V I_{v}-\mathrm{NDVI}$ threshold value for vegetation;

$\mathrm{P}_{\mathrm{v}}$ - vegetation fraction, calculated based on NDVI values (Equation 2). 


$$
P_{v}=\left[\frac{N D V I-N D V I_{\min }}{N D V I_{\max }-N D V I_{\min }}\right]^{2}
$$

Where:

$\mathrm{Pv}$ - vegetation fraction in a pixel at a given location, after Yu et al. (2014);

NDVI - NDVI pixel value at a given location;

NDVImin - NDVI threshold value equivalent to pure built-up pixels (0.05);

NDVImax - NDVI threshold value equivalent to pure vegetated pixels (0.5).

Water vapour values derived from the Near Infrared Total Precipitable Water Vapour

Test Result (MOD05_L2) dataset derived from Terra MODIS used for atmospheric correction of Landsat 8 images are listed in Table 1 below.

Table 1 Mean and standard deviation of water vapour values of Milton Keynes (MK), Bedford (BD) and Luton (LT) for the four dates of interest $\left[\mathrm{g} \mathrm{cm}^{-2}\right]$

\begin{tabular}{rlll}
\hline Date & MK & BD & LT \\
\hline 06-Jun-13 & $1.741 \pm 0.0062$ & $1.625 \pm 0.0071$ & $1.808 \pm 0.0033$ \\
08-Jul-13 & $3.392 \pm 0.0056$ & $3.494 \pm 0.0088$ & $3.436 \pm 0.0039$ \\
01-Feb-14 & $0.838 \pm 0.0049$ & $0.746 \pm 0.0018$ & $0.721 \pm 0.0020$ \\
19-Jan-15 & $0.696 \pm 0.0023$ & $0.722 \pm 0.0019$ & $0.669 \pm 0.0018$ \\
\hline
\end{tabular}




\section{Section 2 Spectral indices used in LST downscaling.}

Table 1 List of LST predictors used in LST downscaling for Milton Keynes, Bedford and Luton.

\begin{tabular}{|c|c|c|}
\hline Spectral Index & Formula* & References \\
\hline $\begin{array}{l}\text { Normalised Difference } \\
\text { Vegetation Index }\end{array}$ & $N D V I=\frac{(N I R-R e d)}{(N I R+R e d)}$ & $\begin{array}{l}\text { (Purevdorj et al., } \\
1998)\end{array}$ \\
\hline $\begin{array}{l}\text { Normalised Difference } \\
\text { Built-Up Index (NDBI) }\end{array}$ & $N D B I=\frac{(S W I R 1-N I R)}{(S W I R 1+N I R)}$ & Zha et al. (2003) \\
\hline Clay minerals ratio & $C M R=\frac{S W I R 1}{S W I R 2}$ & Drury (1987) \\
\hline Ferrous minerals ratio & $F M R=\frac{S W I R 1}{N I R}$ & \\
\hline Iron Oxide Ratio & $I O R=\frac{\text { Red }}{\text { Blue }}$ & \\
\hline $\begin{array}{l}\text { Built-Up Area Extraction } \\
\text { Index (BAEI) }\end{array}$ & $B U A E I=\frac{(\operatorname{Red}+L)}{(\text { Green }+ \text { SWIR } 1)}$ & $\begin{array}{l}\text { Bouzekri et al. } \\
(2015)\end{array}$ \\
\hline Percent Manmade (MNMD) & $\begin{array}{l}\text { Percentage of either water or } \\
\text { impervious land cover features }\end{array}$ & $\begin{array}{l}\text { Chun and } \\
\text { Guldmann (2014) }\end{array}$ \\
\hline Percent Water (WTR) & $\begin{array}{l}\text { within } 2 \mathrm{~m} \text { resolution pixels } \\
\text { derived from OS MasterMap }\end{array}$ & \\
\hline
\end{tabular}

*Blue - band 2 equivalent of Landsat 8, 0.45-0.51 $\mu \mathrm{m}$; Green - band 3 equivalent of Landsat 8, 0.53-0.59 $\mu \mathrm{m}$; Red - band 4 equivalent of Landsat 8, 0.63-0.67 $\mu \mathrm{m}$; NIR - band 5 equivalent of Landsat $8,0.85-0.88 \mu \mathrm{m}$; SWIR 1 - band 6 equivalent of Landsat $8,1.57-$ $1.65 \mu \mathrm{m}$; SWIR 2 - band 7 equivalent of Landsat 8, 2.11-2.29 $\mu \mathrm{m} ; \mathrm{L}-$ an arithmetic constant equal to 0.3 . 


\section{Section 3 Results of the adjustment of the very high resolution spectral}

indices for the temporal mismatch caused by different dates of aerial and satellite data acquisition

Table 1 Correlation coefficients calculated between pairs of spectral indices derived from the Landsat 8 imagery and (1) aggregated original spectral indices derived from hyperspectral imagery (Orig.), (2) aggregated adjusted spectral indices derived from very high resolution hyperspectral imagery (Adj.), and (3) differences in the magnitude of the correlation coefficients calculated between adjusted and original spectral indices (Diff.). Negative values of the differences indicate cases were the adjustment procedure decreased the resemblance of the original very high resolution spectral indices to the equivalent indices derived from satellite data.

\begin{tabular}{|c|c|c|c|c|c|c|c|c|c|c|}
\hline \multirow{2}{*}{ ะี } & \multirow{2}{*}{$\begin{array}{l}\text { Town } \\
\text { Spectral index }\end{array}$} & \multicolumn{3}{|c|}{ Bedford } & \multicolumn{3}{|c|}{ Luton } & \multicolumn{3}{|c|}{ Milton Keynes } \\
\hline & & Orig. & Adj. & Diff. & Orig. & Adj. & Diff. & Orig. & Adj. & Diff. \\
\hline \multirow{6}{*}{ 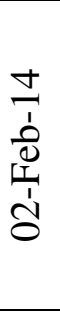 } & BUAEI & 0.10 & 0.36 & 0.26 & 0.13 & 0.51 & 0.38 & 0.15 & 0.49 & 0.34 \\
\hline & CMR & 0.36 & 0.40 & 0.04 & 0.35 & 0.34 & -0.01 & 0.37 & 0.27 & -0.10 \\
\hline & FMR & 0.10 & 0.96 & 0.86 & 0.21 & 0.89 & 0.69 & 0.37 & 0.91 & 0.53 \\
\hline & IOR & 0.27 & 0.68 & 0.41 & 0.47 & 0.67 & 0.19 & 0.31 & 0.58 & 0.27 \\
\hline & NDBI & 0.07 & 0.90 & 0.83 & 0.17 & 0.75 & 0.58 & 0.33 & 0.63 & 0.30 \\
\hline & NDVI & 0.30 & 0.74 & 0.44 & 0.31 & 0.56 & 0.25 & 0.47 & 0.61 & 0.14 \\
\hline \multirow{6}{*}{ 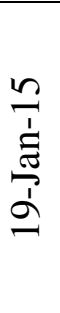 } & BUAEI & 0.15 & 0.29 & 0.14 & 0.18 & 0.44 & 0.25 & 0.24 & 0.47 & 0.23 \\
\hline & CMR & 0.40 & 0.35 & -0.05 & 0.33 & 0.28 & -0.05 & 0.38 & 0.20 & -0.18 \\
\hline & FMR & 0.19 & 0.95 & 0.76 & 0.20 & 0.91 & 0.71 & 0.40 & 0.43 & 0.03 \\
\hline & IOR & 0.31 & 0.33 & 0.01 & 0.45 & 0.69 & 0.24 & 0.35 & 0.49 & 0.15 \\
\hline & NDBI & 0.17 & 0.86 & 0.70 & 0.18 & 0.81 & 0.63 & 0.36 & 0.57 & 0.21 \\
\hline & NDVI & 0.39 & 0.70 & 0.31 & 0.32 & 0.50 & 0.18 & 0.49 & 0.48 & -0.01 \\
\hline \multirow{6}{*}{$\frac{m}{\frac{m}{1}}$} & BUAEI & 0.36 & 0.67 & 0.31 & 0.52 & 0.81 & 0.30 & 0.47 & 0.81 & 0.35 \\
\hline & CMR & 0.71 & 0.72 & 0.02 & 0.72 & 0.73 & 0.01 & 0.64 & 0.59 & -0.06 \\
\hline & FMR & 0.25 & 0.76 & 0.51 & 0.11 & 0.98 & 0.86 & 0.52 & 0.97 & 0.44 \\
\hline & IOR & 0.23 & 0.91 & 0.68 & -0.05 & 0.91 & 0.96 & 0.23 & 0.86 & 0.63 \\
\hline & NDBI & 0.19 & 0.99 & 0.80 & 0.05 & 0.96 & 0.91 & 0.46 & 0.87 & 0.40 \\
\hline & NDVI & 0.53 & 0.86 & 0.33 & 0.37 & 0.83 & 0.46 & 0.65 & 0.76 & 0.11 \\
\hline \multirow{6}{*}{ 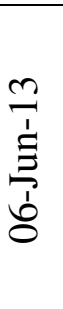 } & BUAEI & 0.33 & 0.70 & 0.37 & 0.44 & 0.83 & 0.39 & 0.49 & 0.80 & 0.31 \\
\hline & CMR & 0.67 & 0.76 & 0.09 & 0.71 & 0.43 & -0.28 & 0.64 & 0.58 & -0.05 \\
\hline & FMR & 0.36 & 0.98 & 0.62 & 0.29 & 0.96 & 0.67 & 0.55 & 0.95 & 0.41 \\
\hline & IOR & 0.35 & 0.96 & 0.61 & 0.23 & 0.84 & 0.61 & 0.38 & 0.86 & 0.48 \\
\hline & NDBI & 0.32 & 0.97 & 0.65 & 0.23 & 0.96 & 0.73 & 0.51 & 0.87 & 0.37 \\
\hline & NDVI & 0.59 & 0.88 & 0.29 & 0.49 & 0.84 & 0.35 & 0.69 & 0.81 & 0.13 \\
\hline
\end{tabular}


Figures 1 to 4

Scatterplots and Pearson correlation coefficients calculated between pairs of spectral indices derived from the Landsat 8 imagery and (1) aggregated original spectral indices derived from hyperspectral imagery (dark grey, dashed regression line and cursive $r$ values), (2) aggregated adjusted spectral indices derived from very high resolution hyperspectral imagery (light grey, solid regression line and bold r values). BD, LT, MK denote Bedford, Luton and Milton Keynes, respectively. $\mathrm{X}$ axis refers to the values of indices derived from hyperspectral aerial imagery, both original and adjusted for values of Landsat 8 indices at a given date, and $\mathrm{Y}$ axis shows the values of Landsat 8 derived spectral indices. Aggregation of spectral indices derived from aerial imagery refers to averaging of the fine resolution pixel values over $30 \mathrm{~m}$ resolution grid cells aligned with Landsat 8 pixels carried out with the purpose of matching the spatial scales of these indices. 

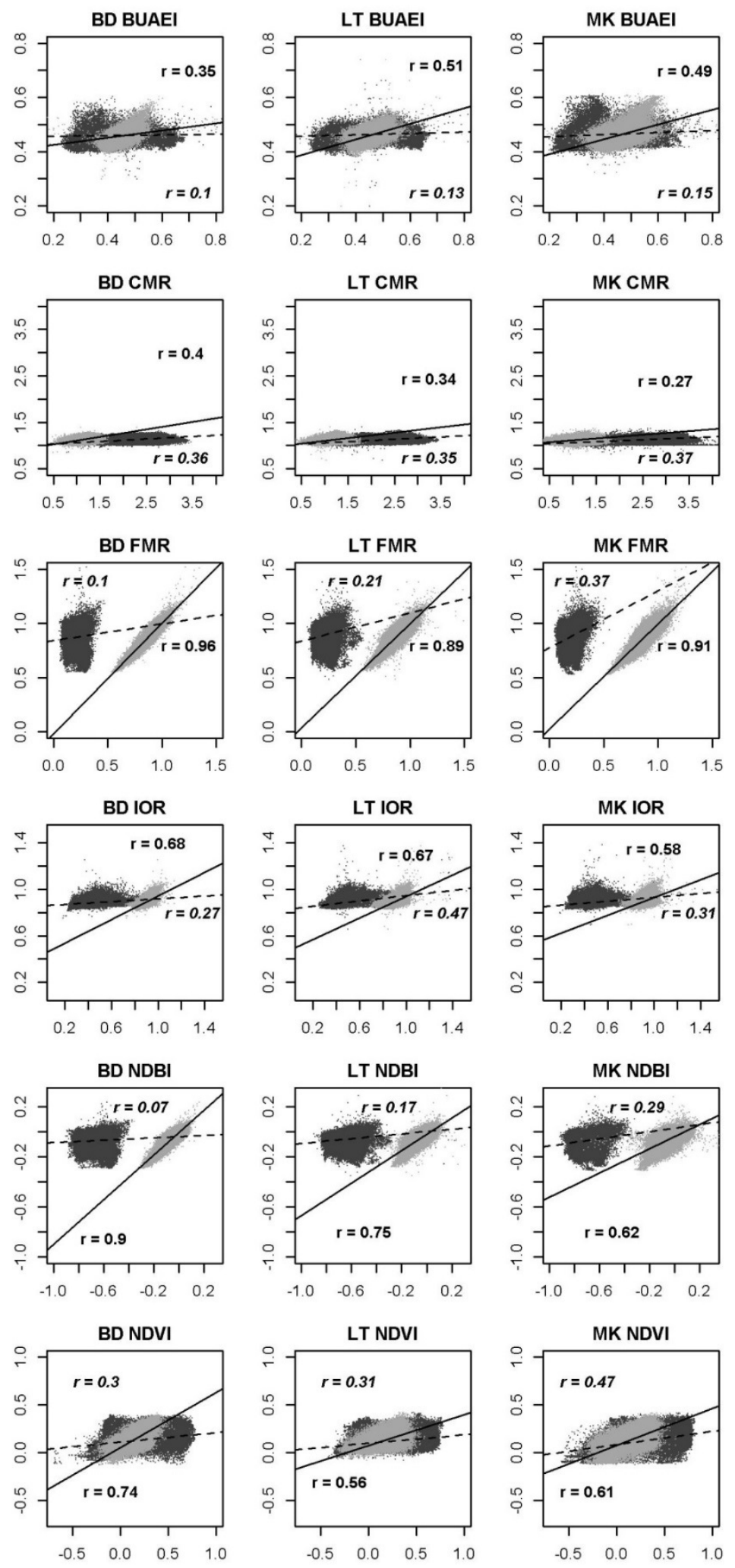

Figure 1 Comparison of Landsat 8 spectral indices (y axis) with equivalent aggregated spectral indices derived from aerial imagery ( $\mathrm{x}$ axis) before (dark grey, dashed regression line) and after (light grey, solid regression line) adjustment for the values of Landsat 8 indices for satellite data captured on $02 \mathrm{Feb} 2014$. Full explanation of the figure given in the first paragraph of Section 3. 

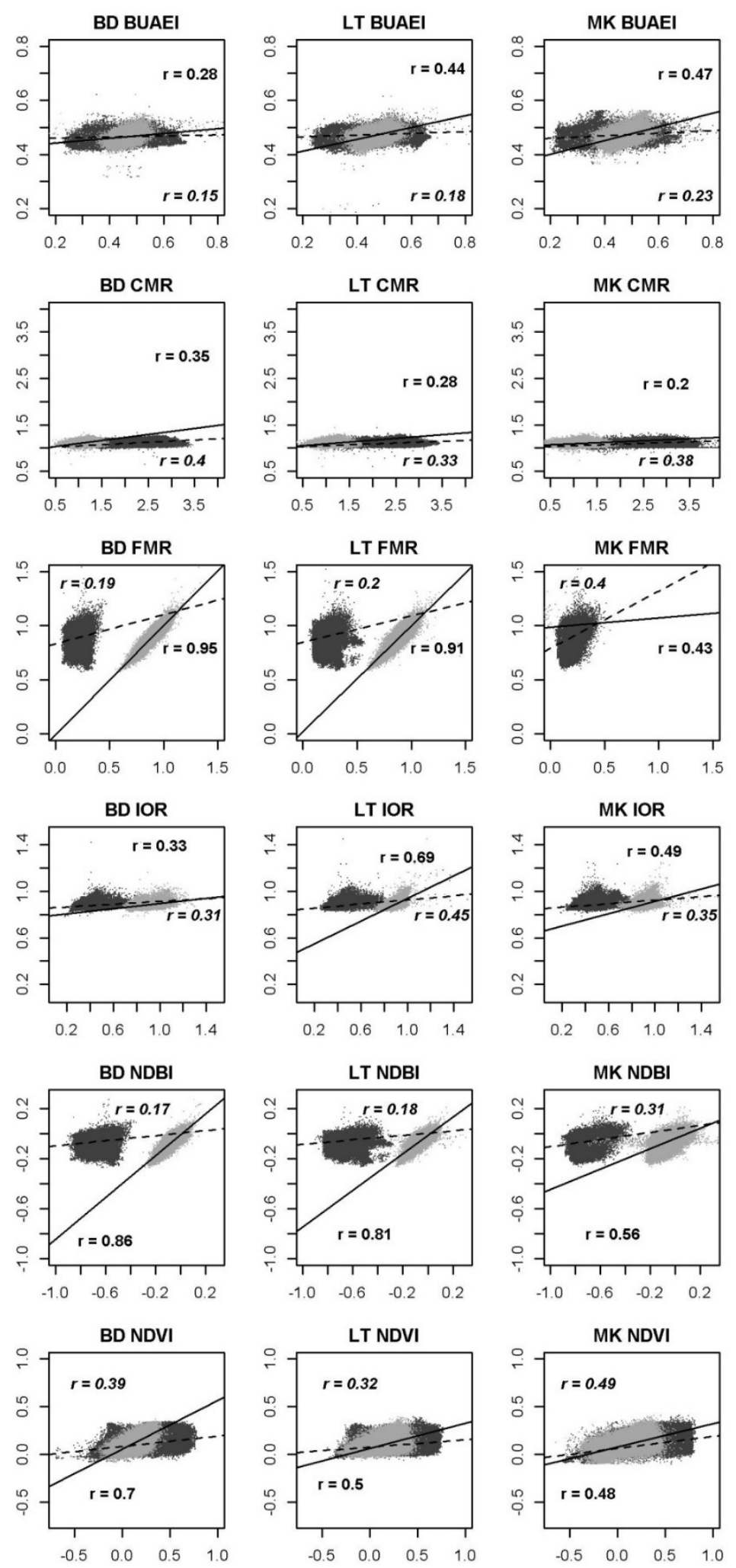

Figure 2 Comparison of Landsat 8 spectral indices (y axis) with equivalent aggregated spectral indices derived from aerial imagery ( $\mathrm{x}$ axis) before (dark grey, dashed regression line) and after (light grey, solid regression line) adjustment for the values of Landsat 8 indices for satellite data captured on 19 Jan 2015. Full explanation of the figure given in the first paragraph of Section 3. 

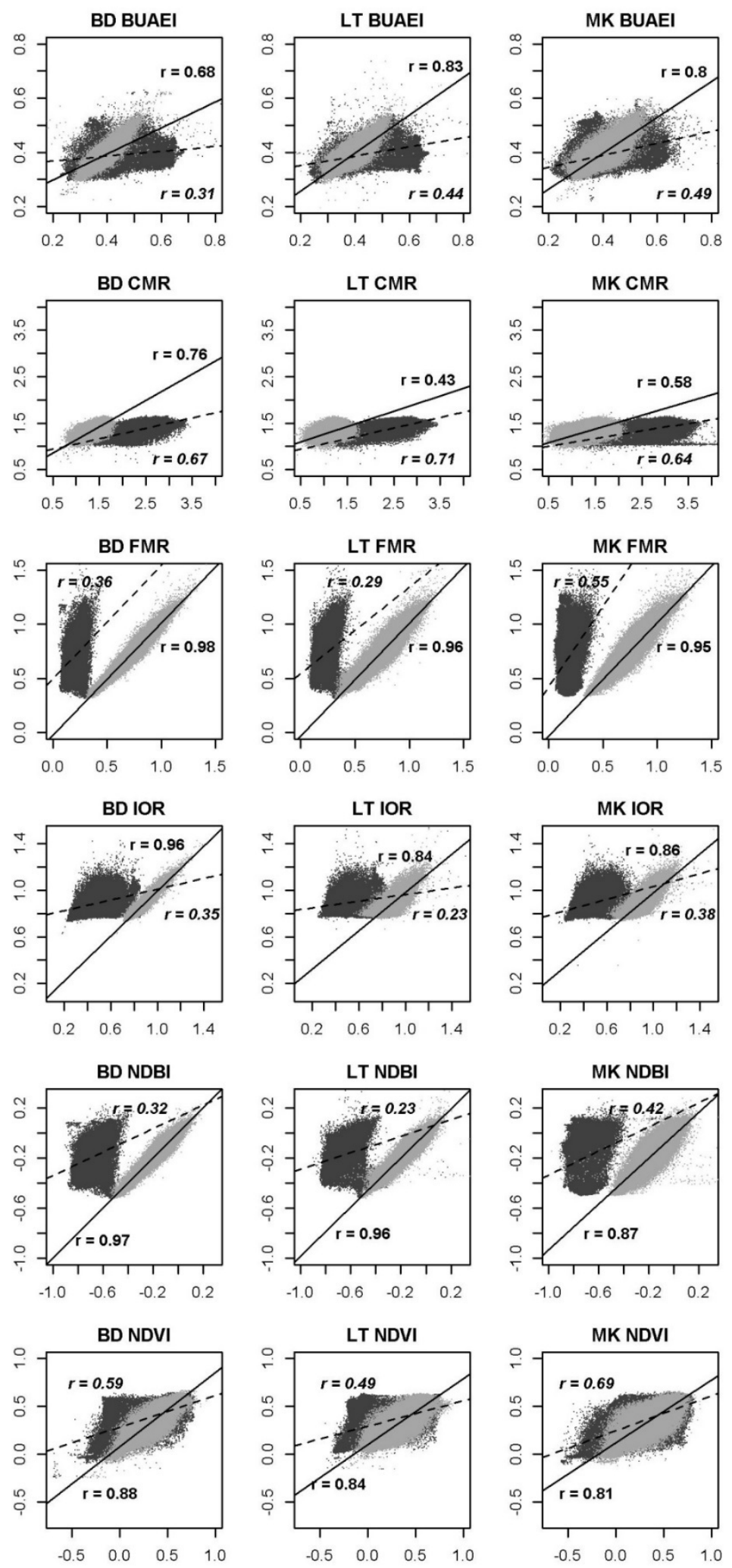

Figure 3 Comparison of Landsat 8 spectral indices (y axis) with equivalent aggregated spectral indices derived from aerial imagery ( $\mathrm{x}$ axis) before (dark grey, dashed regression line) and after (light grey, solid regression line) adjustment for the values of Landsat 8 indices for satellite data captured on 06 Jun 2013. Full explanation of the figure given in the first paragraph of Section 3. 

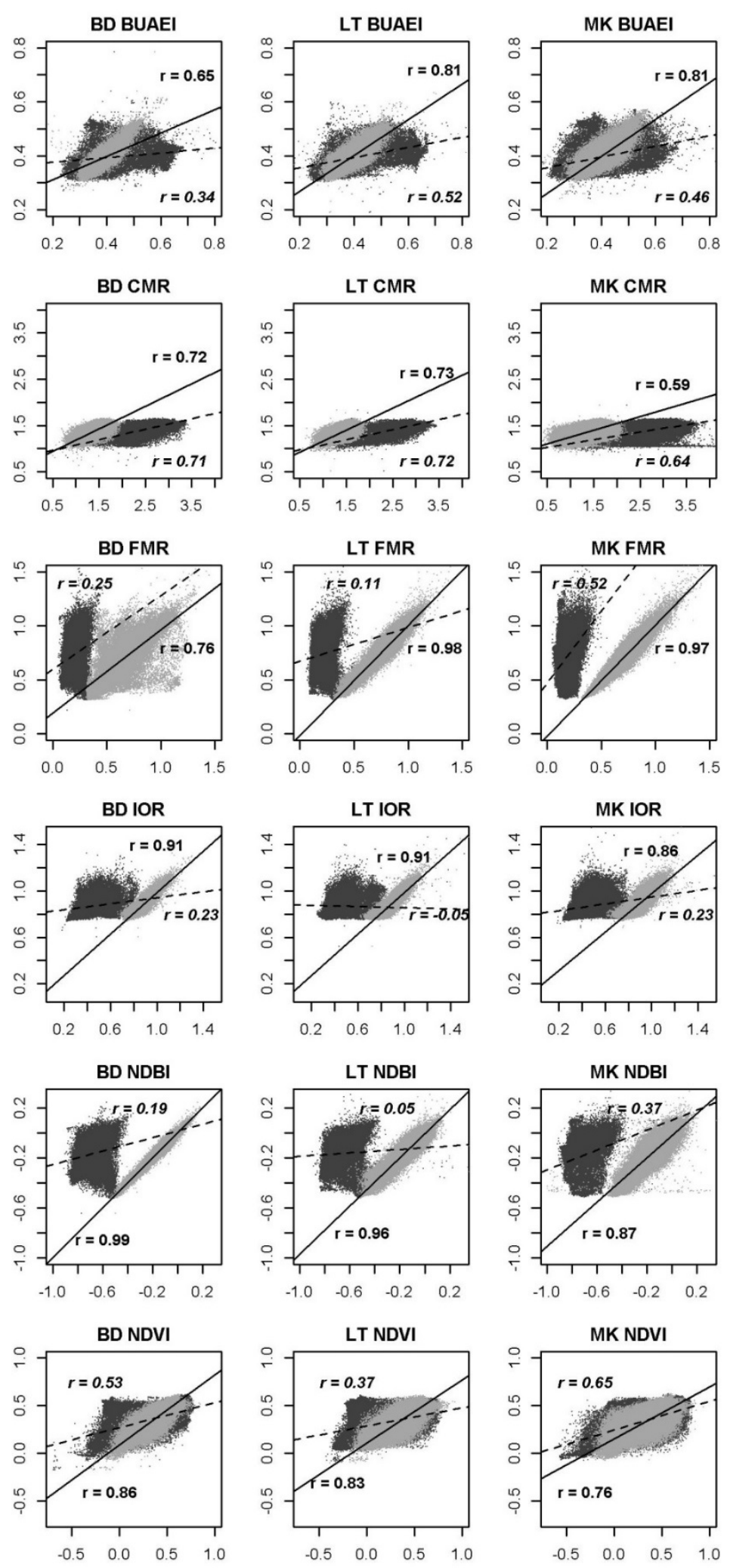

Figure 4 Comparison of Landsat 8 spectral indices (y axis) with equivalent aggregated spectral indices derived from aerial imagery ( $\mathrm{x}$ axis) before (dark grey, dashed regression line) and after (light grey, solid regression line) adjustment for the values of Landsat 8 indices for satellite data captured on 08 Jul 2013. Full explanation of the figure given in the first paragraph of Section 3. 


\section{Section 4 Predictor importance in MARS models used in LST downscaling}

Table 1 MARS equations, generated with Statistica software, used for LST downscaling in Bedford.

\footnotetext{
Bedford, 02 Feb 2014

LST_FEB_BD $=9.35352629553633 \mathrm{e}+000+$

$8.95683970005979 e-004 * \max (0$, mnmd_BD $-2.25480804443359 e+001)$ -

$5.24097858788039 \mathrm{e}-003^{*} \max (0,2.25480804443359 \mathrm{e}+001-\mathrm{mnmd}$ BD $)$ -

$6.39257449247337 \mathrm{e}-002 * \max \left(0, \mathrm{CMR} \_\mathrm{FEB} \_\mathrm{BD}-1.14625322818756 \mathrm{e}+000\right)$ -

$1.97833755719236 \mathrm{e}-001{ }^{*} \max \left(0,1.14625322818756 \mathrm{e}+000-C M R \_F E B \_B D\right)+$

$5.13936482567572 \mathrm{e}-001 * \max (0$, BUAEI_FEB_BD-4.63528275489807e-001) +

$1.28112609091631 \mathrm{e}-001 * \max (0,4.63528275489807 \mathrm{e}-001-B U A E I$ FEB_BD $)$ -

$1.53055292433981 e+002 * \max (0$, wtr_BD-9.99995269775391e+001) +

$7.18288508889315 e-004 * \max \left(0,9.99995269775391 e+001-w t r \_B D\right)+$

$5.75716901596961 \mathrm{e}-002 * \max (0$, IOR_FEB_BD-9.55171287059784e-001) -

$6.07758245703217 \mathrm{e}-001 * \max \left(0,9.55171287059784 \mathrm{e}-001-I O R \_F E B \_B D\right)+$

$8.35419390247879 \mathrm{e}-001 * \max \left(0, N D V I \_F E B \_B D-2.74427950382233 e-001\right)$ -

$1.53167276534035 \mathrm{e}-001 * \max (0,2.74427950382233 \mathrm{e}-001-\mathrm{NDVI} F \mathrm{FEB}$ BD $)$ -

$2.83158217979280 e-001 * \max \left(0, N D B I \_F E B \_B D+1.75494760274887 e-001\right)$ -

$1.18777247787260 e+000 * \max \left(0,-1.75494760274887 \mathrm{e}-001-N D B I \_F E B \_B D\right)$ -

$5.29308626464895 e-001 * \max \left(0, N D V I \_F E B \_B D+9.92088541388512 e-002\right)$ -

$1.08476597446567 e+000 * \max (0$, BUAEI_FEB_BD-5.37508726119995e-002)
}

\section{Bedford, 19 Jan 2015}

LST_JAN_BD $=7.67710168366022 \mathrm{e}+000-$

$5.15358008203914 \mathrm{e}-002 * \max (0$, wtr_BD-4.99985694885254e+001) -

$2.32889703826208 e-002 * \max \left(0,4.99985694885254 \mathrm{e}+001-w t r \_B D\right)+$

$1.22429063438004 \mathrm{e}-003 * \max \left(0, \mathrm{mnmd} \_B D-2.25636844635010 \mathrm{e}+001\right) \quad-$

$4.62090199942209 \mathrm{e}-003 * \max \left(0,2.25636844635010 \mathrm{e}+001-\mathrm{mnmd} \_\mathrm{BD}\right)+$

$3.20428497508927 \mathrm{e}-002 * \max (0$ ，IOR_JAN_BD-1.08994817733765e+000) -

$1.33310358542313 e+000 * \max \left(0,1.08994817733765 e+000-I O R \_J A N \_B D\right)$ -

$1.47578273637958 \mathrm{e}+000 * \max (0$, BUAEI_JAN_BD-1.37384325265884e-001) +

$5.16325893811117 \mathrm{e}-002 * \max (0,1.37384325265884 \mathrm{e}-001-B U A E I$ JAN_BD $)$ -

$3.06548876037324 \mathrm{e}-001 * \max \left(0, N D B I \_J A B \_B D-1.28105878829956 \mathrm{e}-002\right)$ -

$1.48713379538319 \mathrm{e}+000 * \max (0,1.28105878829956 \mathrm{e}-002-\mathrm{NDBI}$ JAB_BD $)+$

$1.39500578663435 e+000 * \max (0$, NDVI_JAN_BD $-2.54180788993835 e-001)-$

$8.34433388312855 e-001 * \max (0,2.54180788993835 e-001-N D V I$ JAN_BD $)+$

$9.44891659946003 e-002 * \max (0$, wtr_BD-7.66757125854492e+001) -

$5.00234878377148 \mathrm{e}-002{ }^{*} \max (0$, CMR_JAN_BD-9.53488469123840e-001) -

$3.46980646092921 \mathrm{e}-001 * \max \left(0,9.53488469123840 \mathrm{e}-001-C M R \_J A N \_B D\right)$ -

$1.55869193420676 \mathrm{e}+000 * \max (0$, NDVI_JAN_BD+9.30313616991043e-002) +

$1.17235457230060 \mathrm{e}+000 * \max (0, \mathrm{NDVI}$ JAN_BD-9.47636365890503e-002)

\section{Bedford, 06 Jun 2013}

LST_JUN_BD $=2.74564456032957 \mathrm{e}+001+$

$1.37938421732014 \mathrm{e}+001 * \max (0$, NDBI_JUN_BD+1.87999784946442e-001) -

$2.52902501544114 \mathrm{e}+001 * \max (0,-1.87999784946442 \mathrm{e}-001-\mathrm{NDBI}$ _UN_BD $)+$

$1.66761967051721 e-001 * \max (0$, wtr_BD $-5.00000000000000 e+001)+$

$8.60664731142638 e-002 * \max \left(0,5.00000000000000 e+001-w t r \_B D\right)+$

$1.77456437982270 e+001 * \max (0$, NDVI_JUN_BD-4.48368877172470e-001) -

$6.36015439521035 e+000 * \max \left(0,4.48368877172470 \mathrm{e}-001-N D V I \_J U N \_B D\right)+$

$2.76197213946934 \mathrm{e}-003{ }^{*} \max \left(0, \mathrm{mnmd} \_\mathrm{BD}-2.27888813018799 \mathrm{e}+001\right)$ -

$6.02990743682226 \mathrm{e}-002 * \max \left(0,2.27888813018799 \mathrm{e}+001-\mathrm{mnmd} \_\mathrm{BD}\right)$ -

$1.55125110166977 \mathrm{e}+000 * \max (0$, IOR_JUN_BD-9.44522440433502e-001) -

$6.74228152875435 \mathrm{e}+000 * \max \left(0,9.44522440433502 \mathrm{e}-001-I O R \_J U N \_B D\right)$ -

$1.18416114227356 \mathrm{e}+001 * \max (0$, NDBI_JUN_BD-3.24028730392456e-003) -

$4.06784516593544 \mathrm{e}-001 * \max (0$, CMR_JUN_BD-9.62374210357666e-001) -

$2.82586472120663 e+000 * \max \left(0,9.62374210357666 \mathrm{e}-001-C M R \_J U N \_B D\right)$ -

$2.91665710400558 \mathrm{e}-001 * \max (0$, wtr_BD $-7.68483734130859 e+001)+$

$9.63784567429320 e+000 * \max (0$, BUAEI_JUN_BD-5.04963397979736e-001) + 
$1.31102542804218 e+000 * \max \left(0,5.04963397979736 e-001-B U A E I \_J U N \_B D\right)$ -

4.90719999627658e+000*max(0, NDVI_JUN_BD-4.32529188692570e-002)

\section{Bedford, 08 Jul 2013}

LST_JUL_BD $=3.85861563882998 \mathrm{e}+001+$

$1.39898352692557 e+001 * \max \left(0, N D B I \_J U L \_B D+7.42961764335632 e-002\right)$ -

$2.35034260145147 e+001 * \max (0,-7.42961764335632 \mathrm{e}-002-\mathrm{NDBI}$ _UUL_BD $)$ -

$8.95147565943523 e+000 * \max (0$, mnmd_BD $-4.90942627191544 \mathrm{e}-001)+$

$1.86981556674656 \mathrm{e}+001 * \max (0,4.90942627191544 \mathrm{e}-001-$ mnmd_BD $)+$

$7.03244444064443 e+000 * \max \left(0, N D V I \_J U L \_B D-4.72034811973572 \mathrm{e}-001\right)$ -

$9.81329721276825 \mathrm{e}-001 * \max \left(0,4.72034811973572 \mathrm{e}-001-N D V I \_J U L \_B D\right)+$

$4.63012299453887 e+000 * \max (0$, IOR_JUL_BD-8.82818639278412e-001) -

$1.13724079701179 \mathrm{e}+001 * \max \left(0,8.82818639278412 \mathrm{e}-001-I O R \_\right.$UUL_BD $)$-

$9.98256939558051 \mathrm{e}+000 * \max (0$, BUAEI_JUL_BD-2.89033681154251e-001) -

$6.21249132903780 e-001 * \max (0,2.89033681154251 e-001-B U A E I$ JUL_BD $)$ -

$1.53884775181943 e+000 * \max \left(0, C M R \_J U L \_B D-9.28904712200165 \mathrm{e}-001\right)$ -

$2.01226835550789 e+000 * \max \left(0,9.28904712200165 e-001-C M R \_J U L \_B D\right)+$

$1.75638761919558 \mathrm{e}+000 * \max (0$, CMR_JUL_BD-1.45547020435333e+000) +

$2.68184447275441 e-002 * \max (0$, wtr_BD-4.99985694885254e+001) +

$1.97807334813855 \mathrm{e}-002{ }^{*} \max \left(0,4.99985694885254 \mathrm{e}+001-w t r \_B D\right)+$

$1.00287328497026 \mathrm{e}+001 * \max (0$, BUAEI_JUL_BD-5.13547539710999e-001) -

$6.13881362926549 e+000 * \max (0, \mathrm{NDBI}$ JUL_BD-2.72986888885498e-002)

Table 2 MARS equations, generated with Statistica software, used for LST downscaling in Luton.
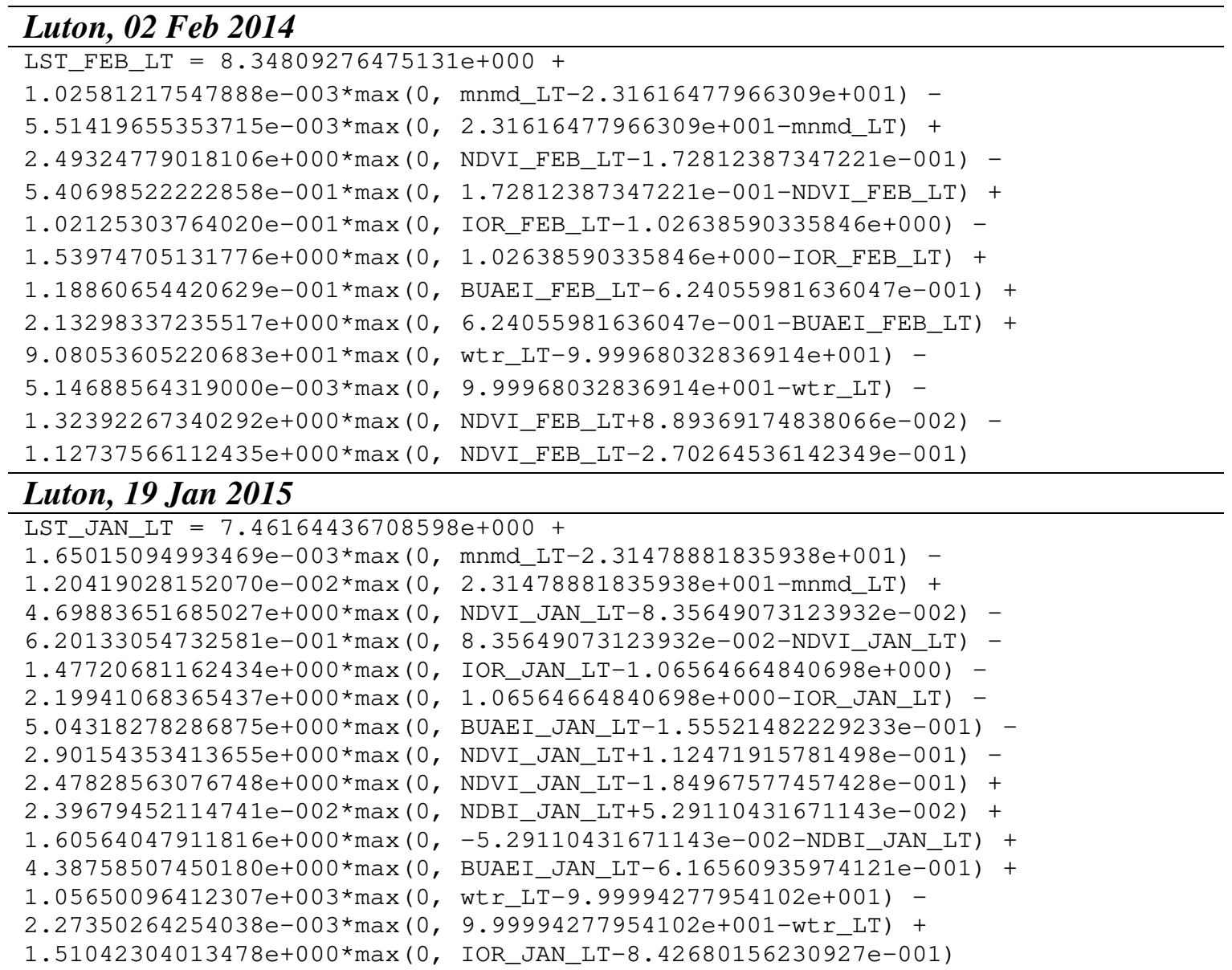




Table 3 MARS equations, generated with Statistica software, used for LST downscaling in Milton Keynes.

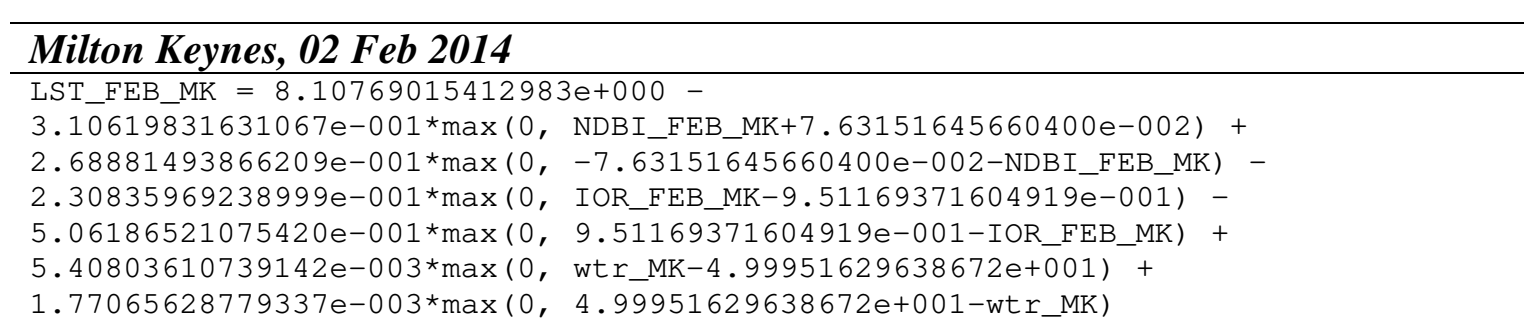




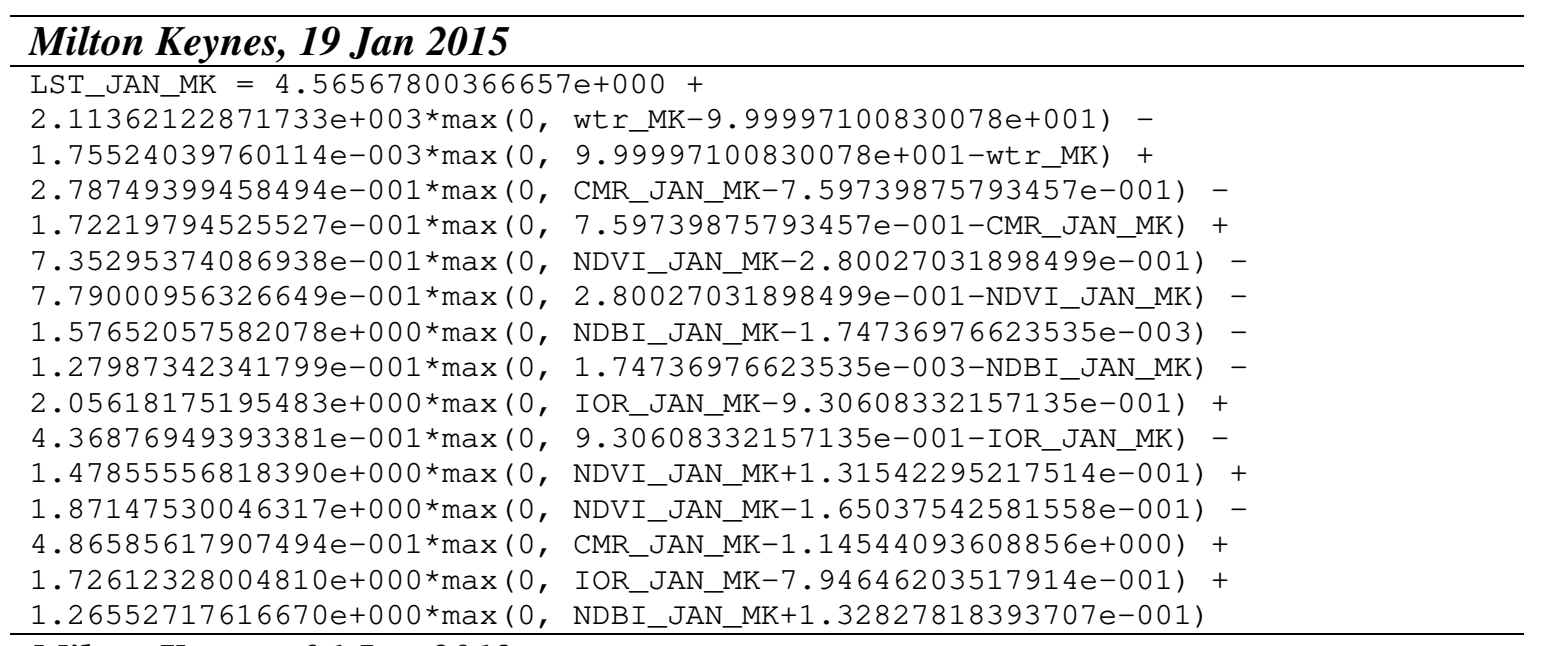

\section{Milton Keynes, 06 Jun 2013}

LST_JUN_MK $=3.16145325502259 \mathrm{e}+001+$

$5.00512031560374 e+000 * \max \left(0, N D B I \_J U N \_M K+3.51608991622925 e-002\right)$ -

$1.56567633163297 \mathrm{e}+001 * \max (0,-3.51608991622925 \mathrm{e}-002-\mathrm{NDBI}$ _UUN_MK $)$ +

$1.39179842479948 e+001 * \max \left(0, N D V I \_J U N \_M K-4.75337445735931 \mathrm{e}-001\right)$ -

$1.28662705555742 e+000 * \max \left(0,4.75337445735931 \mathrm{e}-001-N D V I \_J U N \_M K\right)$ -

$2.09373196914596 e+004 * \max (0$, wtr_MK-9.99999008178711e+001) +

$1.60000211454816 e-002 * \max \left(0,9.99999008178711 e+001-w t r \_M K\right)+$

$7.13789186921252 \mathrm{e}-001 * \max (0$, CMR_JUN_MK-8.48855078220367e-001) -

$2.95003930425920 e+000 * \max \left(0,8.48855078220367 e-001-C M R \_J U N \_M K\right)+$

$3.16899856950515 e-003 * \max \left(0, \mathrm{mnmd} \_M K-2.17027015686035 e+001\right)$ -

$4.22726522010481 \mathrm{e}-002 * \max (0,2.17027015686035 \mathrm{e}+001-\mathrm{mnmd}$ MKK $)+$

$3.78557088036876 \mathrm{e}+000 * \max (0$, IOR_JUN_MK-9.14385676383972e-001) -

$1.01888761248971 \mathrm{e}+001{ }^{*} \max \left(0,9.14385676383972 \mathrm{e}-001-I O R \_J U N \_M K\right)+$

$1.21102374635811 \mathrm{e}+001 * \max (0$, BUAEI_JUN_MK-5.13219833374023e-001) +

$3.93010792397706 \mathrm{e}+000 * \max \left(0,5.13219833374023 \mathrm{e}-001-B U A E I \_J U N \_M K\right)$ -

$7.81921419847556 e+000 * \max (0$, NDVI_JUN_MK-4.63529378175735e-002) -

$8.08360037250700 e+000 * \max (0$, NDBI_JUN_MK+2.04050838947296e-001) -

$1.38445015709328 \mathrm{e}+001 * \max (0$, BUAEI_JUN_MK-3.06692719459534e-001)

\section{Luton, 08 Jul 2013}

LST_JUL_MK $=3.49290373013733 e+001-$

$8.06396552008399 \mathrm{e}-001 * \max (0, \mathrm{NDBI}$ JUL_MK+1.08186483383179e-001) -

$1.36793330751633 e+001 * \max (0,-1.08186483383179 \mathrm{e}-001-\mathrm{NDBI}$-JUL_MK $)+$

$1.14468832876355 e+001 * \max (0$, NDVI_JUL_MK-4.61925178766251e-001) -

$2.16461509622334 \mathrm{e}+000{ }^{*} \max (0,4.61925178766251 \mathrm{e}-001-\mathrm{NDVI}$-JUL_MK) -

$1.62318894331971 e+004 * \max (0$, wtr_MK-9.99999008178711e+001) +

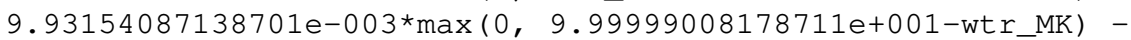

$3.16819938303890 \mathrm{e}-001 * \max (0$, CMR_JUL_MK-8.74632298946381e-001) -

$2.50435355816165 e+000 * \max \left(0,8.74632298946381 \mathrm{e}-001-C M R \_J U L \_M K\right)+$

$3.90368373521225 \mathrm{e}-003{ }^{*} \max \left(0, \mathrm{mnmd} \_\mathrm{MK}-2.17354965209961 \mathrm{e}+001\right)$ -

$3.14110162149845 \mathrm{e}-002 * \max \left(0,2.17354965209961 \mathrm{e}+001-\mathrm{mnmd} \_\right.$MK $)+$

$2.96382485671142 \mathrm{e}+000 * \max (0$, IOR_JUL_MK-8.93855333328247e-001) -

$7.60542475665607 e+000 * \max \left(0,8.93855333328247 e-001-I O R \_J U L \_M K\right)+$

$1.25305929620202 e+001 * \max (0$, BUAEI_JUL_MK-5.53946435451508e-001) -

$2.10180249916012 \mathrm{e}+000 * \max (0,5.53946435451508 \mathrm{e}-001-B U A E I$ JUL_MK $)$ -

$5.65831990899602 \mathrm{e}+000 * \max (0$, NDVI_JUL_MK-1.50935538113117e-002) -

$1.31512797869724 \mathrm{e}+001 * \max (0$, BUAEI_JUL_MK-2.92499601840973e-001) +

$1.20225518173797 e+000 * \max (0$, CMR_JUL_MK-1.44332516193390e+000) 
Table 4 Frequency of use of scaling factors in LST downscaling MARS models developed at 2 to $4 \mathrm{~m}$ resolution.

\begin{tabular}{cccccccccccccc}
\hline Date & \multicolumn{1}{c}{ 06-Jun-13 } & \multicolumn{3}{c}{ 08-Jul-13 } & \multicolumn{3}{c}{ 19-Jan-15 } & \multicolumn{3}{c}{ 02-Feb-14 } \\
\hline $\begin{array}{c}\text { Scaling factor } \\
(\mathbf{2} \text { to 4 } \boldsymbol{m})\end{array}$ & $\boldsymbol{M} \boldsymbol{M}$ & $\boldsymbol{L} \boldsymbol{T}$ & $\boldsymbol{B D}$ & $\boldsymbol{M} \boldsymbol{M}$ & $\boldsymbol{L T}$ & $\boldsymbol{B D}$ & $\boldsymbol{M}$ & $\boldsymbol{L T}$ & $\boldsymbol{B D}$ & $\boldsymbol{M}$ & $\boldsymbol{L T}$ & $\boldsymbol{B D}$ \\
\hline BUAEI & 2 & 2 & 2 & 2 & 2 & 2 & 2 & 3 & 3 & 1 & 2 & 2 \\
CMR & 2 & 2 & 0 & 2 & 2 & 2 & 0 & 0 & 0 & 0 & 2 & 0 \\
FMR & 3 & 3 & 3 & 3 & 3 & 3 & 5 & 2 & 2 & 5 & 3 & 3 \\
IOR & 2 & 3 & 2 & 2 & 3 & 2 & 3 & 3 & 3 & 2 & 2 & 2 \\
MNMD & 2 & 2 & 2 & 2 & 2 & 2 & 2 & 2 & 2 & 0 & 2 & 2 \\
NDBI & 2 & 2 & 2 & 2 & 2 & 3 & 2 & 2 & 3 & 2 & 3 & 3 \\
NDVI & 3 & 2 & 3 & 3 & 2 & 2 & 0 & 3 & 2 & 2 & 2 & 2 \\
WTR & 2 & 2 & 3 & 2 & 2 & 2 & 2 & 0 & 2 & 3 & 0 & 3 \\
\hline $\begin{array}{l}\text { Total number } \\
\text { of references }\end{array}$ & 18 & 18 & 17 & 18 & 18 & 18 & 16 & 15 & 17 & 15 & 16 & 17 \\
\hline
\end{tabular}


Section 5 Performance of LST downscaling models

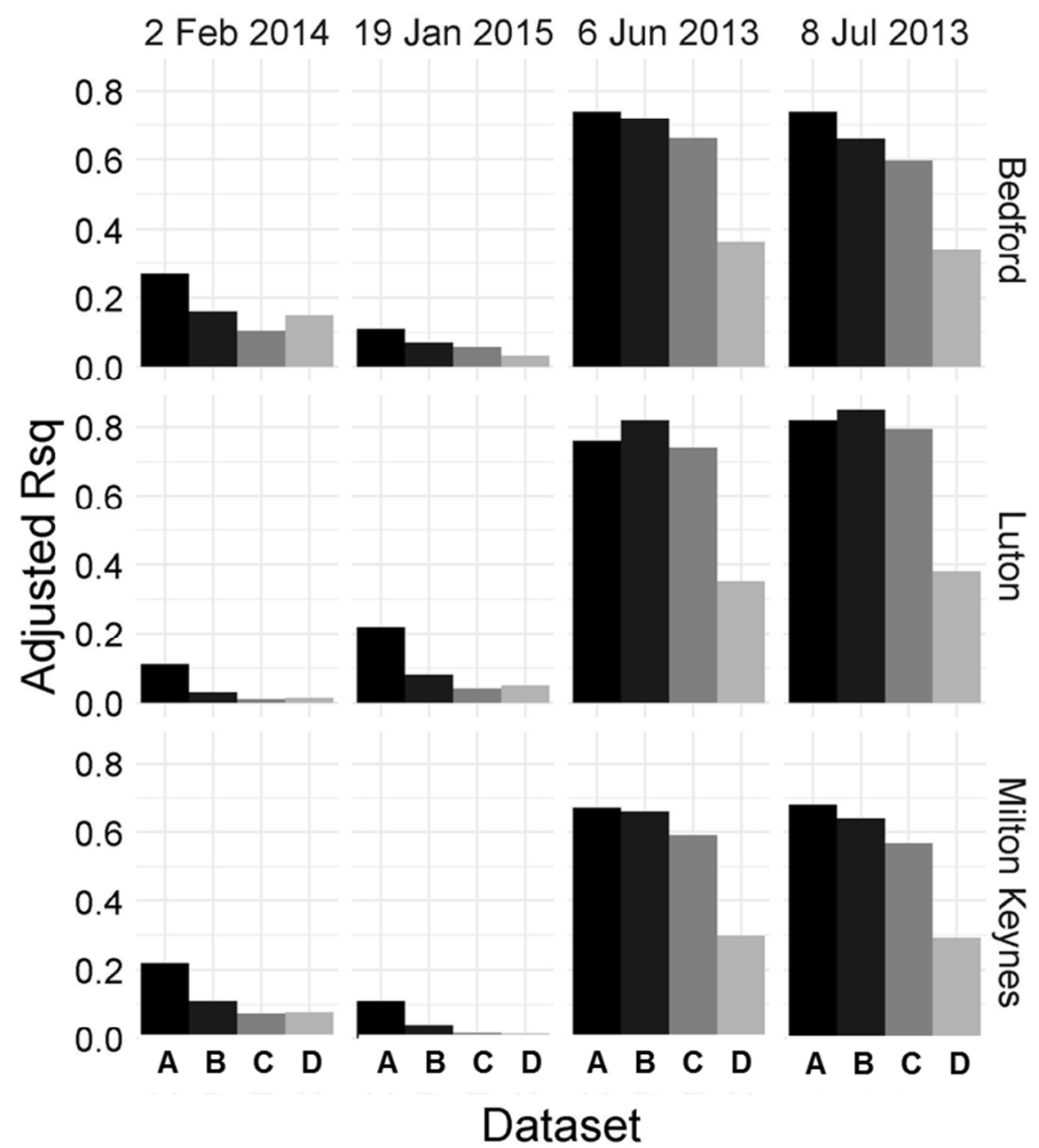

Figure 1 Adjusted R squared for different models tested in the study for all towns and dates: A - MARS 30m, B - MARS 2/4m adjusted, C - multiple regression (MR) 2/4m adjusted, D - MR 2/4m unadjusted. 

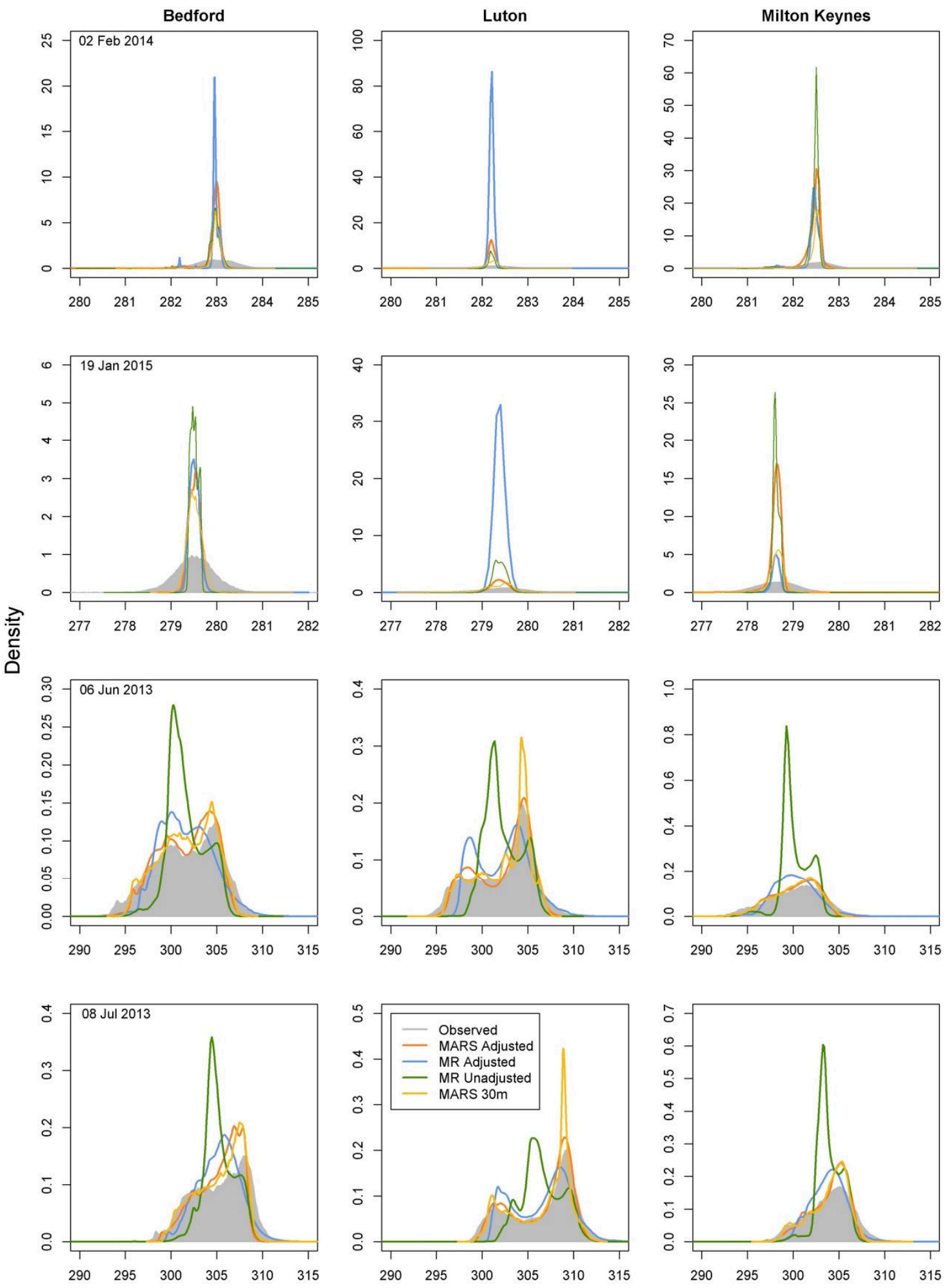

Land Surface Temperature [K]

Figure 1 Distribution of LST values in the Landsat-derived (Observed) and downscaled maps without adjustment for residuals. 


\section{Section 6 Land surface temperature maps}

Table 1 Basic statistics for LST derived from Landsat 8 TIR bands [K].

\begin{tabular}{|c|c|c|c|c|c|c|c|c|c|c|c|c|}
\hline \multicolumn{2}{|c|}{ Date/Town } & \multicolumn{3}{|c|}{02 Feb 2014} & \multicolumn{2}{|c|}{ 19-Jan-15 } & \multicolumn{3}{|c|}{ 06-Jun-13 } & \multicolumn{2}{|c|}{ 08-Jul-13 } & \multirow[b]{2}{*}{ MK } \\
\hline Statistic & $B D$ & $L T$ & MK & $B D$ & $L T$ & MK & $B D$ & $L T$ & MK & $B D$ & $L T$ & \\
\hline Min & 277.7 & 268.7 & 264.1 & 275.2 & 268.2 & 255.9 & 291.4 & 290.2 & 282.6 & 297.2 & 294.8 & 291.6 \\
\hline $\operatorname{Max}$ & 284.5 & 284.1 & 285.2 & 283 & 282.8 & 283.7 & 313.2 & 319.2 & 312.4 & 315.7 & 322.7 & 317.3 \\
\hline Range & 6.8 & 15.4 & 21.1 & 7.8 & 14.6 & 27.8 & 21.8 & 29.0 & 29.8 & 18.5 & 27.9 & 25.7 \\
\hline Mean & 282.9 & 282.2 & 282.5 & 279.5 & 279.4 & 278.6 & 301.6 & 302.2 & 300.2 & 305.2 & 306.5 & 303.9 \\
\hline Std & 0.5 & 0.5 & 0.6 & 0.5 & 0.6 & 0.6 & 3.5 & 3.4 & 3 & 2.9 & 3.6 & 2.6 \\
\hline
\end{tabular}

Table 2 Basic statistics for downscaled LST maps with the $\mathrm{MARS}_{2 / 4 \text { ma }}$ models [K].

\begin{tabular}{l|lll|lll|llll|lll}
\hline \multicolumn{1}{l}{ Date/Town } & \multicolumn{4}{c}{ O2 Feb 2014 } & \multicolumn{1}{c}{ 19-Jan-15 } & \multicolumn{3}{c}{ 06-Jun-13 } & \multicolumn{3}{c}{ 08-Jul-13 } \\
\hline Statistic & $\boldsymbol{B D}$ & $\boldsymbol{L T}$ & $\mathbf{M K}$ & $\boldsymbol{B D}$ & $\boldsymbol{L T}$ & $\boldsymbol{M K}$ & $\boldsymbol{B D}$ & $\boldsymbol{L T}$ & $\boldsymbol{M K}$ & $\boldsymbol{B D}$ & $\boldsymbol{L T}$ & $\boldsymbol{M K}$ \\
\hline Min & 278.6 & 278.4 & 275.2 & 278.7 & 277.3 & 273.9 & 289.4 & 292.4 & 288.1 & 290.9 & 297.4 & 294.0 \\
Max & 285.9 & 285.3 & 300.9 & 280.5 & 282.2 & 287.3 & 317.6 & 331.0 & 313.7 & 313.8 & 329.6 & 316.4 \\
Range & 7.2 & 6.9 & 25.7 & 1.8 & 4.8 & 13.4 & 28.2 & 38.5 & 25.5 & 22.9 & 32.2 & 22.4 \\
Mean & 282.9 & 282.2 & 282.5 & 279.5 & 279.4 & 278.6 & 301.6 & 302.2 & 300.2 & 305.2 & 306.5 & 303.9 \\
Std & 0.2 & 0.1 & 0.2 & 0.1 & 0.2 & 0.1 & 2.9 & 3.0 & 2.5 & 2.4 & 3.3 & 2.1 \\
\hline
\end{tabular}




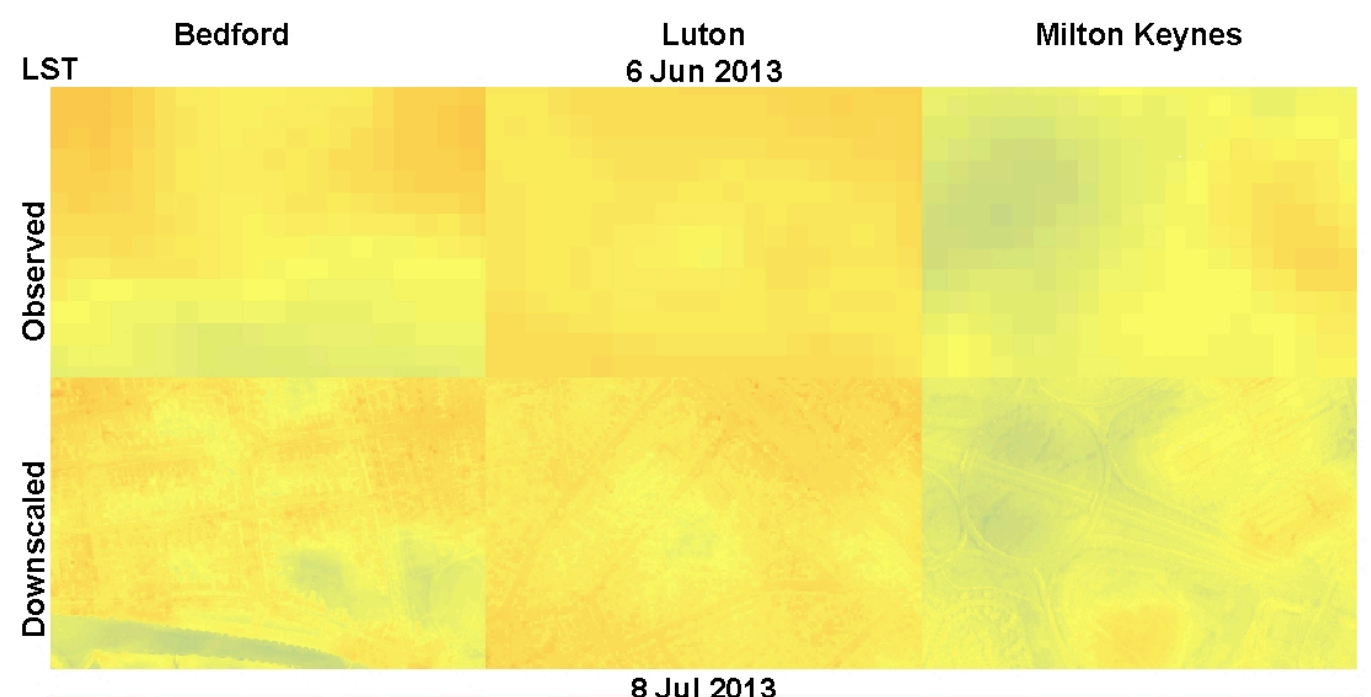

8 Jul 2013

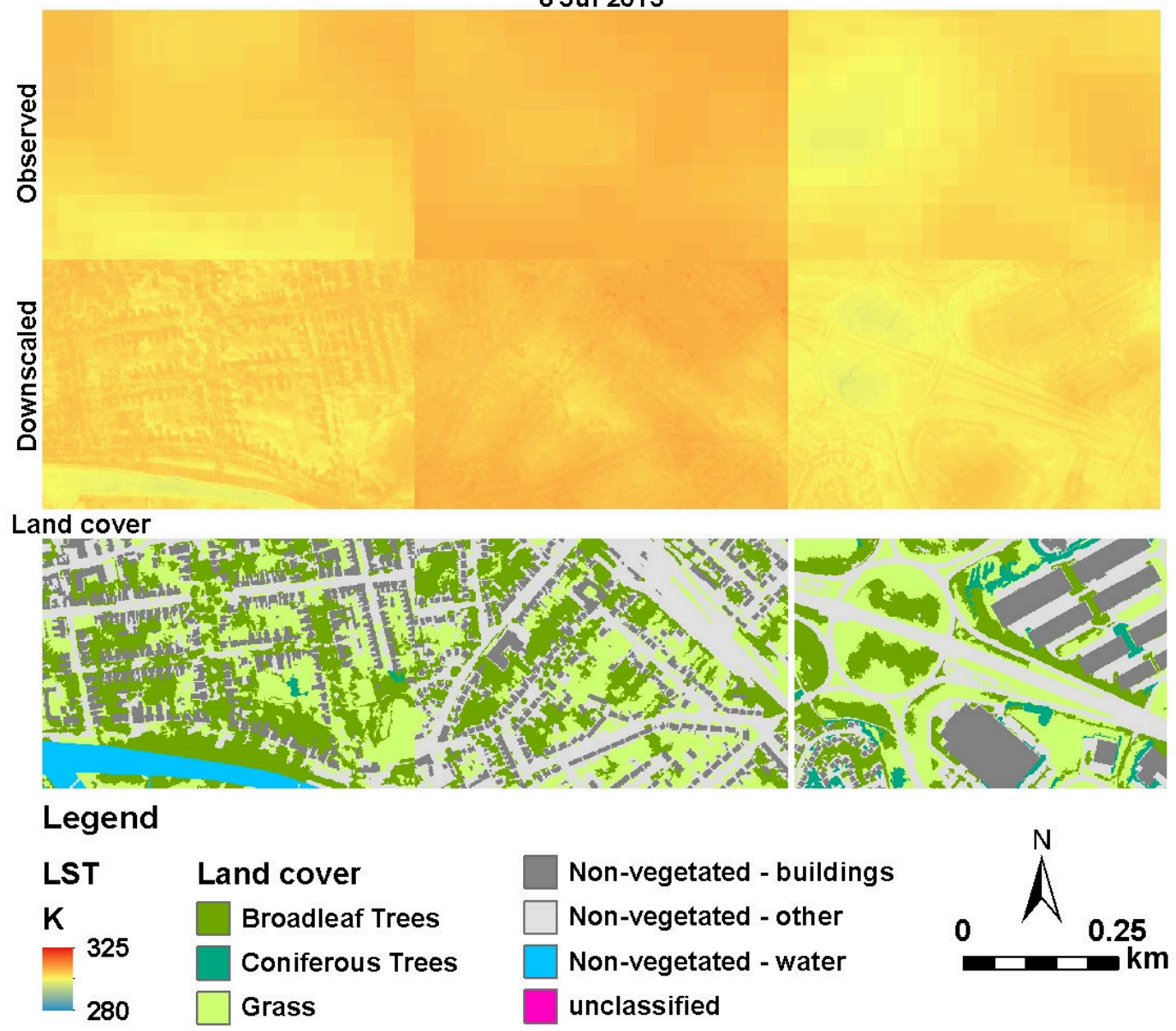

Figure 2 Large-scale comparison of the LST downscaled maps with the MARS method at target 2 to $4 \mathrm{~m}$ spatial resolution for summer dates. 
References

Bouzekri, S., Lasbet, A.A., Lachehab, A., 2015. A New Spectral Index for Extraction of Built-Up Area Using Landsat-8 Data. J. Indian Soc. Remote Sens. 43, 867-873. https://doi.org/10.1007/s12524-015-0460-6

Chun, B., Guldmann, J.-M., 2014. Spatial statistical analysis and simulation of the urban heat island in high-density central cities. Landsc. Urban Plan. 125, 76-88. https://doi.org/10.1016/j.landurbplan.2014.01.016

Drury, S.A. (Stephen A.., 1987. Image interpretation in geology. Allen \& Unwin.

Purevdorj, T., Tateishi, R., Ishiyama, T., Honda, Y., 1998. Relationships between percent vegetation cover and vegetation indices. Int. J. Remote Sens. 19, 35193535. https://doi.org/10.1080/014311698213795

Sobrino, J.A., Jiménez-Muñoz, J.C., Sòria, G., Romaguera, M., Guanter, L., Moreno, J., Plaza, A., Martínez, P., 2008. Land surface emissivity retrieval from different VNIR and TIR sensors. pp. 316-327. https://doi.org/10.1109/TGRS.2007.904834

Yu, X., Guo, X., Wu, Z., 2014. Land Surface Temperature Retrieval from Landsat 8 TIRS - Comparison between Radiative Transfer Equation-Based Method, Split Window Algorithm and Single Channel Method. Remote Sens. 6, 9829-9852. https://doi.org/10.3390/rs6109829

Zha, Y., Gao, J., Ni, S., 2003. Use of normalized difference built-up index in automatically mapping urban areas from TM imagery. Int. J. Remote Sens. 24, 583-594. https://doi.org/10.1080/01431160304987 